\title{
INTERFERENCIAS DE LAS CORTES CONSERVADORAS ANTE EL PRETENDIENTE CARLISTA*
}

\author{
José RAMÓN URQUIJO GOITIA \\ Instituto de Historia (CSIC)
}

RESUMEN: A lo largo de la Primera Guerra Carlista bubo varios intentos de finalizar el conflicto mediante una transacción, cuyos contenidos variaban desde el arreglo personal mediante un matrimonio hasta la concesión foral. La evolución política del campo liberal obligó a variar los términos de las propuestas. Tras la reunión de Toeplitz las Potencias Conservadoras remitieron a don Carlos una petición de clarificación y modificación de su ideario, a fin de hacerlo más atractivo a sectores moderados españoles y defendible ante la opinión pública europea. La negativa a cualquier cambio restó apoyos y credibilidad a la causa carlista en Europa.

PALABRAS ClAVE: Primera Guerra Carlista. Relaciones internacionales. Ideología carlista. Austria. Prusia. Rusia. CerdeñaPiamonte.

* El presente artículo ha sido realizado en el seno del proyecto Paz en la Guerra (negociaciones de paz y escisiones en los grupos políticos en el primer carlismo) (HUM2004-03184) financiado por la Dirección General de Investigación del Ministerio de Educación y Ciencia. Abreviaturas de los archivos citados en el presente trabajo: A.H.N. Archivo Histórico Nacional (Madrid), A.M.R.E Archives du Ministère des Relations Extèrieures (París); A.R.A.H. Archivo de la Real Academia de la Historia (Madrid); A.S.M.A.E. Archivio Storico del Ministero degli Affari Esteri (Roma); A.S.N.Archivio di Stato di Napoli (Nápoles); A.S.T. Archivio di Stato di Torino (Turín); B.N.P. Bibliothèque Nationale (Paris); H.H.St.A. Haus-, Hof-und Staatsarchiv (Viena); P.R.O. Public Record Office (Kew, Londres). Además se utilizan las siguientes abreviaturas: AA.EE. Affari Esteri; C.P. Correspondance Politique.; C.P.D. Carte Politiche Diverse; F.O. Foreign Office; G.A. Gesandtschaftsarchiv von; LL.MM. Lettere Ministri; M.A.E. Ministro / Ministerio de Asuntos Exteriores; M.D.S.T. Missioni diplomatiche speciali e temporarie; Mss. Manuscrits; R.P.Ch. Registre des pièces chiffrées (volumi della corrispondenza in partenza); S.S. Segreteria di Stato. En las citas provenientes de periódicos, tras la fecha, se incluyen dos números entre paréntesis, el primero corresponde a la página y el segundo a la columna. En algunos casos los nombres de los archivos han variado, pero he conservado el que tenían cuando inicié mis investigaciones. 
ABSTRACT: During the First Carlist War, there were a variety of attempts to end the conflict by negotiation, the contents of which varied from a personal settlement through marriage to the granting of regional privileges. Political developments among the liberals forced the contents of the proposals to change. After the Toeplitz meeting, the Conservative groups asked D. Carlos to clarify and modify his agenda in order to make it more attractive to Spanish moderates as well as acceptable to European public opinion. The refusal to change lost the Carlist cause both support and credibility in Europe.

KEY WORDS: First Carlist War, International Relations, Carlist ideology, Austria, Prussia, Russia, Sardinia.

Desde el momento en que se vislumbró el conflicto sucesorio tanto en el interior como en el exterior surgieron diversas iniciativas encaminadas a evitar el enfrentamiento. En cada fase cronológica las propuestas diferían, teniendo en cuenta las variaciones políticas implantadas en el campo liberal ${ }^{1}$. Las primeras se limitaban fundamentalmente a plantear matrimonios entre los herederos, pero tras el inicio de la guerra empezaron a introducirse planteamientos que suponían modificaciones políticas, destinadas a contentar a los partidarios del bando contrario. Junto a estas iniciativas encontramos una variante de las mismas consistente en proclamas, que sin implicar a los jefes contrarios permitiesen a sus seguidores encontrar atractiva la iniciativa, es decir, minar sus apoyos y adquirir una legitimación ante la comunidad internacional.

El canciller Metternich no adoptó una política clara de apoyo a la causa carlista, porque no estaba de acuerdo con los principios absolutistas que parecía defender don Carlos. Su pensamiento estaba impregnado de las ideas de su consejero político Friedrich Gentz, artífice de la idea de equilibrio y de moderación, a la cual deseaban empujar al Pretendiente: «Le teoria la vera teoria dell'equilibrio politico è interamente costruita su idee di moderazione, di reciproca limitazione, di controllo e conservazione» ${ }^{2}$.

Desde esa posición se realizaron diversas tentativas para que los carlistas moderasen su mensaje político, porque no deseaban que se repitiese la situación represiva de la Restauración de 1823.

Una perpetuación de los sistemas represivos podía ser nefasta para la estabilidad europea, pues, en su opinión, una de las causas de la Revolución Francesa se encontraba en «la impotencia y los errores del gobierno» ${ }^{3}$.

\footnotetext{
1 Sobre las distintas propuestas véase Urquijo Goitia, José Ramón. «Antecedentes del abrazo de Vergara».- En : 150 años del Convenio de Vergara y de la ley de 25-X-1839.- Vitoria = Gasteiz : Parlamento Vasco = Eusko Legebiltzarra, 1990; p. 227-267.

${ }^{2}$ Gentz, Friedrich. Sulla pace perpetua / a cura di Maria Pia Paternò.- Camerino : Università degli Studi di Camerino, 1992; p. 55.

${ }^{3}$ Gentz, Friedrich. Dos revoluciones. La Revolución Norteamericana comparada con la Revolución Francesa / traducción de Rigoberto Juárez-Paz.- Madrid : Unión Editorial, 1989; p. 51. Paternò,
} 


\section{TRANSACCIONES Y PROPUESTAS DE MODIFICACIÓN POLÍTICA.}

Uno de los primeros testimonios en los que se habla de la necesidad de modificaciones políticas en el carlismo, lo encontramos en las declaraciones de Eraso a los agentes franceses que le interrogaron en octubre de 1833, tras el fracaso inicial de su sublevación en Navarra, quien planteaba la posibilidad de una renuncia de don Carlos y el matrimonio de entre su hijo y su sobrina:

«...que Don Carlos abdiquant en faveur de son fils, celui-ci, épousât la Reine Isabelle et qu'un conseil de Régence composé sous l'influence de la France et de l'Angleterre ou même de la France seule, prît une grande mesure tout à la fois de diplomatie et de haute administration, d'après laquelle la nation serait consultée ou par la voix des anciennes Cortés ou par la voix de nouvelles qui parâtraient au Conseil mieux adoptées à l'expression libre des vœux de toutes les classes pour connaître et déterminer la forme du Gouvernement définitif à donner à l'Espagne. Tout faisant au nom de la légitimité, des institutions nouvelles pourraient être introduites sans résistance» 4

A pesar de que el funcionario francés señalaba que las palabras de Eraso no le inspiraban excesiva confianza, parece cierto que algunos carlistas no se oponían a una solución en la que se pactasen ciertas modificaciones, que diesen luz a un sistema diferente al seguido por el monarca fallecido.

Entre los temas recurrentes de las Cortes conservadoras que apoyaban a don Carlos se encontraba la necesidad de publicar un manifiesto en el que se aclarasen las intenciones políticas del Pretendiente para cuando estuviese en el Trono. La primera propuesta fue realizada por el Vizconde de Canellas, Fco. T. Calomarde y Valentín de Verástegui:

«Repetimos ahora este primer deber de lealtad, añadiendo que la opinión general entre el Cuerpo Diplomático Extranjero, entre todos los publicistas, y demás políticos por realistas que sean es: que V. M. no puede en el día vencer los obstáculos que la revolución del siglo en que vivimos, ha sembrado en el camino de su Augusto Trono, sin prometer ostensiblemente y del fondo de su noble corazón, como acostumbra siempre:

$1^{\circ}$.- No intervenir de modo alguno en los negocios interiores de las demás Potencias.

$2^{\circ}$.- Restituir a las Provincias sus antiguos fueros, aumentando aún los de Navarra y Provincias Vascongadas.

$3^{\circ}$.- Dar una amnistía general sin excepción de persona de todo lo pasado hasta el día de la publicación y conocimiento del manifiesto.

\footnotetext{
Maria Pia. Friedrich Gentz e la rivoluzione francese-- Roma : Università degli Studi «la Sapienza», 1993; p. 20-21.

${ }_{4}^{4}$ A.M.R.E. C.P. Espagne 761. Carta del Prefecto de los Bajos Pirineos (31.10.1833) al Ministro del Interior.
} 
$4^{\mathrm{o}}$.- Reconocer todos los empréstitos y deudas legítimas del Estado y reputadas como tal por su Augusto Hermano.

$5^{\circ}$.- Proclamar la más estricta neutralidad en todos los negocios interiores de las Potencias Extranjeras; cumplir exactamente los tratados; favorecer el comercio, industria y demás relaciones extranjeras sin perjuicio del comercio e industria nacional»s.

Unos meses más tarde (30 de enero de 1835), el Vizconde de Canellas insistía en la necesidad de la publicación del manifiesto.

La crisis política que llevó a los tories a desempeñar el gobierno británico llenó de esperanza a los carlistas, quienes tuvieron que soportar la tremenda desazón de ver quebrarse sus esperanzas. Dos fueron los motivos de esta situación: la concepción de la política respecto a España como una cuestión de estado, especialmente tras la firma del Tratado de la Cuádruple Alianza, y el escaso entusiasmo con que veían el inmovilismo político de don Carlos.

El nuevo Gobierno británico retomó la idea de una negociación para finalizar la guerra mediante un acuerdo. Si bien no hay constancia de los términos en que se realizó la propuesta, testimonios indirectos nos permiten reconstruir los hechos de forma exacta. El agente carlista en Bayona, Lagracinière, transmitía a finales de enero de 1835 una carta enviada desde Inglaterra en la que se detallaban las gestiones realizadas por el general Álava en Londres, hasta el punto de haber logrado hacer variar al Lord Wellington sus principios de actuación con respecto al conflicto español:

«Amigo mío parece que no hay duda el que Álava ha conseguido del Duque de Wellington el mandar un Comisario a España ( $\mathrm{y}$ aún dicen su nombre el Lord Fitzroy Somerset) para hacer proposiciones de una naturaleza tal como la siguiente: a S. M. que se retire de la contienda y que el Príncipe de Asturias ha de casarse con la Isabella mediante el cual sería marido de la Reina pero no Rey a menos que consienta a todo cuanto se ha hecho de Estatuto Real etc.; probablemente propondrán un armisticio desde luego. Si estas proposiciones tan ridículas y ofensivas al honor, carácter e inviolables derechos de S. M. no fuesen aceptadas que entonces un ejército francés entrará en España para poner fin a la guerra.

Puedo estar equivocado en el pormenor de las proposiciones pero algo hay sur le tapis. Ya ha hablado de ello el Albion que se supone el jornal (sic) del Duque»6.

5 A.R.A.H. 9/6721. Carta enviada por Francisco Tadeo Calomarde, Vizconde de Canellas y Valentín de Verástegui (20.07.1834) a don Carlos. A.R.A.H. 9/6723. Carta enviada por el vizconde de Canellas y el conde de Almaida (12.09.1834) a don Carlos; Carta enviada por el vizconde de Canellas y el conde de Almaida (19.09.1834) a Carlos Cruz Mayor. En ambas se insiste en el mismo tema e incluso en la segunda se adjunta un borrador de proclama.

${ }^{6}$ A.R.A.H. 9/6700. La carta firmada por L. tiene fecha de 29 de enero de 1835. Parecido testimonio nos proporciona el representante sardo en Viena en carta a su Ministro, $\mathrm{n}^{\circ} 33$ de 15.02.1835. (Original en A.S.T. LL.MM. Austria 133. Borrador en A.S.M.A.E. S.S. Sardegna Ambasciata Vienna 56): "Vous serez, Monsieur le Comte, informé directement de Londres des démarches qui ont été faites auprès de Lord Wellington pour l'engager à soutenir le projet de 
De acuerdo con el testimonio del Nuncio en Viena, tal iniciativa, en opinión de Metternich, tenía su origen no en Wellington, sino en el «justo medio» francés y español. A lo cual, añadía el diplomático vaticano, había respondido don Carlos que jamás sería aceptada ninguna propuesta de arreglo ${ }^{7}$. La carta del responsable carlista de Asuntos Exteriores enviada al Lord Wellington no dejaba lugar a posibles dudas tanto de su postura al respecto como de la existencia de insinuaciones por parte de los conservadores de Gran Bretaña:

«...y puede haber transacción con semejante gente? puede haber término medio en ideas tan encontradas? Los intereses se pueden conciliar, mas no los principios que son de eterna justicia; y no es dado al ingenio humano amalgamar estos con la perversa condición»8.

Más claro resultaba el texto de las instrucciones preparadas para el representante carlista ante la Corte de los Zares, Fernando de Navia:

«Verdad es que aun en medio del estruendo de la guerra el Gobierno de S.M. no ha ignorado tampoco las ideas que algunos de los Embajadores del Norte en París han creído poder adelantar con respecto a la marcha que deberíamos seguir para arreglar nuestros negocios, ideas extrañas por no decir otra cosa, en representantes de unas monarquías puras, a las que por su naturaleza debería repugnar toda especie de innovaciones en materia de instituciones de otros Gobiernos análogos a los suyos, ideas que aunque no han sido convertidas en proposiciones, ni

mariage entre le Fils de l'Infant D. Carlos et la fille de la Reine Christine; le noble Lord qui avait énoncé dans le temps un avis contraire parait aujourd'hui persuadé par les raisonnements du général Alava, qu'ont peut essayer ce moyen de rapprochement, Mgr. l'Evêque de Leon a consulté sur ce point Mr. le Comte de l'Alcudia et l'avis de ce dernier, motivé sur ce que les personnes intéressées Lui ont dit dans le temps, a été que ni la Reine ni l'Infant ne voudraient se prêter à cet arrangement; arrangement au reste qui pourrait bien, venant à s'effectuer, fondre les partis de la Reine et de l'Infant, mais que ne réunissait jamais les deux véritables partis existants en Espagne, celui de l'ordre et celui du désordre». La misma opinión tenía el represente de Cerdeña en París, conde de Blonay, quien dando cuenta de dichos rumores (A.S.T. LL.MM. Francia 261. despacho $\mathrm{n}^{\circ} 1165$ de 16.02.1835) señalaba que la correspondencia inglesa hablaba de un intento de arreglo de la guerra de España mediante la conciliación de don Carlos y María Cristina, y la boda de sus hijos primogénitos. Añadía que desconocía la oficialidad del tema que suponía al menos tratado «en conversation, sans intention formelle de la part de ceux qu'étaient supposés la mettre en avant». Y concluía la información juzgando irrealizable el proyecto, porque no satisfacía las exigencias de ningún partido.

7 A.S.V. S.S. Esteri (247) 407. Despacho del Nuncio (20.02.1835 n $\left.\mathrm{n}^{\circ} 335\right)$. a la Secretaría de Estado El periódico italiano La Vocce della Verità 24.02.1835, pág. 1269, publicaba un testimonio similar: «Al Quartier Reale di Carlo V si conoscono le proposizioni di transazione fatte dal generale Alava al Duca di Wellington: queste proposisioni falliranno. Carlo V rifiuterà ogni mediazione di questa sorte, e non ascolterà proposizione che assiso sul suo trono. I suoi fedeli non vi acconsentirebbero mai, no mai: essi conoscono il Re che divide i loro pericoli, apprezzano il suo coraggio e le sue nobili virtù, e sanno quante speranze siano con lui, e non si sottopporranno mai ad alcuna reggenza. Essi si inquietano aasai poco della Europa...».

8 A.R.A.H. 9/6717. Carta de Cruz Mayor (16.01.1835) a Lord Wellington. 
transmitidas directamente a S.M., no por eso han dejado de causarle una sensación desagradable.

...le prevengo que por ningún motivo ni en modo alguno nuestro digno Monarca accederá a proposiciones que tengan por objeto o la más mínima cesión de sus derechos y de sus prerrogativas soberanas; o el enlace de S.S. A.A. R.R. los Serenísimos Señores Infantes, sus Augustos hijos, con las Hijas de la Reina viuda; o la más leve desmembración de parte alguna de sus dominios; o una modificación, sea la que fuere, en nuestras instituciones y en nuestras leyes fundamentales»?.

A continuación se indicaba la primera medida que pensaba adoptar: declarar nulos todos los actos del gobierno posteriores a la muerte de Fernando VII. Y concretando más mencionaba la nulidad de las operaciones financieras y la negativa absoluta a la concesión de una amnistía.

Cuando Flórez tuvo en sus manos las instrucciones de 10 de febrero se entrevistó con Solaro para solicitar el reconocimiento, como ya lo había hecho en diversas ocasiones desde agosto del año anterior, en que había iniciado el ejercicio de su representación. A los razonamientos utilizados añadía ahora el de la excelente situación militar en que se encontraba el Pretendiente; la explicación de «los sabios principios que S.M. Católica se propone seguir» y «la política que observará en cuanto a sus relaciones con las Potencias extranjeras» ${ }^{10}$. Temas todos ellos que eran objeto de preocupación de las Potencias Conservadoras. Pero Solaro no estaba dispuesto a desligarse de la política que había seguido hasta el momento de pleno acuerdo con Austria.

En la primavera de 1835, el general Córdoba realizó un viaje a Madrid desde los cuarteles en que se encontraba el Ejército del Norte con el fin de plantear al Gobierno la necesidad de reclamar la intervención francesa, que se concretaría en una ocupación de ciertos valles y plazas. Sin embargo se esparcían numerosos rumores sobre la posibilidad de la negociación política de la guerra, razón por la cual el Conde de Alcudia solicitó instrucciones:

«Las diferentes versiones que se dan al viaje de Córdova a Madrid, y negociaciones de transacción, de que los periódicos le suponen encargado, exigen con urgencia se dé conocimiento a los Agentes del Rey, si en ello no hay inconveniente mayor, qué es lo que hay de positivo en la materia: esto es si Córdova está autorizado por el Rey para proponer transacciones, lo que no creo, y si en el caso que el Gobierno usurpador las haga al Rey cuáles serán las admisibles para que con arreglo a la voluntad del Rey las potencias puedan apoyar o rebatir según la real voluntad»11.

9 A.R.A.H. 9/6705. Las instrucciones están fechadas el 10 de febrero de 1835. Pirala, Antonio. Historia de la guerra civil y de los partidos liberal y carlista.- Madrid : Turner / Historia 16, 1984; vol. III, p. 471-472.

${ }_{10}$ A.R.A.H. 9/6771. Despacho de Gabriel Flórez (20.05.1835 n ${ }^{4}$ ) al M.A.E.

${ }_{11}$ A.R.A.H. 9/6733. Carta cifrada del Conde de Alcudia (25.05.1835) al Secretario de Estado carlista. 
A continuación el diplomático carlista señalaba que en caso de no recibir nuevas instrucciones consideraba que las únicas válidas eran las de que don Carlos debía heredar la Corona en las mismas condiciones que la recibió de su padre, y que no se aceptaba ninguna proposición salvo alguna medida de gracia para quienes habían colaborado con la usurpación sin haberse comprometido en ciertos actos «cuya gravedad por sus mismos hechos los han puesto fuera de la ley».

En mayo de 1835 La Gazette de France reproducía y comentaba, en primera página, un artículo del periódico Temps sobre los rumores existentes. Según el portavoz pro-carlista, la causa liberal se batía en retirada y trataba de salvarse del naufragio negociando una solución honrosa. Dichas gestiones se habían iniciado hacía tiempo, cuando el general Córdova fue comisionado a Madrid por el general Valdés ${ }^{12}$. Las propuestas se podían resumir así: renuncia de don Carlos; matrimonio de su hijo con la reina Isabel; amnistía y mantenimiento de los fueros. Francia e Inglaterra ejercerían el control del acuerdo que sería aprobado por las potencias del Norte.

El articulista comentaba que don Carlos no podía aceptar tales condiciones y se extendía en explicar lo que consideraba el programa político de don Carlos. Insisto en lo de que consideraba porque el Pretendiente carlista se negó en todo momento a explicitar su proyecto político. Según el editorial, don Carlos reuniría Cortes, de acuerdo con la tradición española, que resultaban mucho más libres que las mentirosas instituciones liberales ${ }^{13}$.

Pero además de este editorial exponiendo las novedades de las que hablaba otro periódico, se publicaba un artículo titulado «Nous marchons à la Restauration» para analizar las noticias provenientes de Madrid, que salían a la luz en el Messager ${ }^{14}$. Este periódico señalaba asimismo los rumores de transacción y fijaba casi las mismas condiciones que su colega.

Sin embargo, el diario pro-carlista indicaba que éstos se encontraban próximos a la victoria final, como consecuencia de los sucesivos desastres militares del ejército liberal y de su desmoralización, y planteaba que don Carlos era la única solución para salvar al país del abismo ${ }^{15}$.

${ }^{12}$ La Gazette de France 17.05.1835 (1/1). "Après l'échec de Valdès et l'arrivée de Cordova à Madrid, le conseil de régence et le conseil des ministres ont examiné la situation et délibéré sur le parti à prendre. Il parait que Cordova n'était, au fond, qu'un messager de détresse envoyé par Valdès avec les propositions du vainqueur».

${ }^{13}$ Sobre la idea carlista de la representación véase: Urquijo Goitia, José Ramón. «La representación desde el antiliberalismo».- En: Ayer.- (2006) nº 61; p. 163-187.

${ }^{14}$ La Gazette de France 17.05.1835 (1/2,3).

${ }^{15}$ La Gazette de France 17.05.1835 (1/2,3). «Quelqu'engagés que soient des gouvernements dans les voies de la révolution, la restauration est toujours proche, car ils n'en sont jamais séparés que par un mot. Ce mot qui les sauve de l'abîme, il faut seulement qu'ils le disent à temps». El mismo periódico publicaba una nota aún más explícita, el 21-V-1835 (1/3): «En Espagne, le principe représenté par Don Carlos s'avance à la faveur des querelles entre les partisans de la constitution des Cortes et ceux du statut royal. Don Carlos est devenu la transaction nécessaire entre deux factions qui ne pourraient, sans lui, jamais s'accorder». 
Al día siguiente el mismo periódico volvía a insistir en los principios políticos que informaban el gobierno de Carlos V, que no eran otros que los contenidos en el manifiesto publicado por Fernando VII en 1814 al abolir el sistema constitucional ${ }^{16}$. El periodista indicaba que el Pretendiente carlista había señalado en diversas ocasiones que su propósito era mantener la antiguas instituciones de la monarquía, y para ilustrar dicha afirmación traducía algunos párrafos del Decreto de 4 de mayo de 1814 en los que se sentaban las bases de lo que algunos autores han calificado como una tercera vía, intermedia entre el liberalismo y el absolutismo, recuperando el funcionamiento utópicamente democrático de la monarquía española.

Desde Prusia llegaban constantes insinuaciones de la necesidad de que llegar a una solución pactada del conflicto, en la que se aunaban elementos personales y políticos, signo evidente de la visión que se tenía de los acontecimientos: se proponía una boda entre los hijos y la exigencia a don Carlos «des garanties d'institutions et d'amnistie» ${ }^{17}$.

Las sublevaciones que tuvieron lugar en el verano de 1835, acrecentaron los miedos de los absolutistas europeos y les reafirmaron en la idea de que don Carlos representaba la única solución capaz de evitar el desastre en España ${ }^{18}$. Tales acontecimientos significaban el fracaso del juste milieu intentado en España, por lo que María Cristina se vería en medio de dos fuerzas que se enfrentaban, los carlistas y los liberales. La descripción que hace Sambuy de la situación, resumiendo las conversaciones que había mantenido en Viena especialmente con Metternich, es sin duda la base de las operaciones realizadas por Prusia y Cerdeña para convencer a don Carlos de la necesidad de modificar su línea política de cara a atraer a sectores que temían una represión excesiva en caso de victoria de sus partidarios.

«Tous les gens de bien les ecclésiastiques, les propriétaires etc. tiennent à D. Carlos. Lui seul en Espagne, représente le principe conservative; lui seul est l'ancre du salut, au milieu du naufrage général. Tout l'élite de la nation doit nécessairement se rallier sous se drapeaux» ${ }^{19}$.

${ }^{16}$ La Gazette de France 18.05.1835 (1/2>2/1). El texto del manifiesto en Decretos del Rey Fernando VII / por Fermín Martín de Balmaseda.- Madrid : Imprenta Real, 1818. págs. 1-9.

17 A.M.R.E. C.P. Prusse 286, fol. 31. Despacho del Embajador francés en Berlín (14.06.1835 $\mathrm{n}^{\circ}$ 269) al M.A.E. relatando una entrevista con el Ministro de Asuntos Exteriores prusiano Ancillon. Un testimonio similar en el vol. 285, fol. 241. Despacho del Embajador francés en Berlín (20.02.1835 n $\mathrm{n}^{\circ}$ 240) al M.A.E. A.S.N. AA. EE. 956 Despacho del barón Antonini, Embajador napolitano en Berlín (17.09.1835 $\mathrm{n}^{\circ}$ 148) al M.A.E..

18 A.S.T. LL. MM. Austria 133. Despacho del Conde Sambuy (30.08.1835 n $\left.{ }^{\circ} 51\right)$ al Conde Solaro. «Le cercle des événements s'agrandit de jour en jour en Espagne, et tous les malheurs fondent sur cette misérable contrée. Nous venons d'apprendre les troubles qui ont eu lieu à Madrid le 14 et le 15 courant. Les prévisions du Prince Chancelier se réalisent de tout point. La légitimité est le seul remède contre le débordement de l'anarchie et le renversement total de l'ordre social. Charles V aura à recueillir une large moisson de triomphe et de gloire».

19 A.S.M.A.E. S.S. Sardegna Ambasciata Vienna 58. Borrador del despacho del Conde Sambuy (28.08.1835 n ${ }^{\circ}$ 50) al Conde Solaro. 
Asimismo consideraban que la radicalización política española obligaría a Luis Felipe a decantarse por la causa carlista, ante el peligro de que los demócratas franceses pudieran encontrar en España una base desde la que conspirar contra la monarquía de julio ${ }^{20}$.

\section{Presiones políticas sobre don Carlos.}

Las reuniones de las Potencias Conservadoras eran la gran esperanza de los carlistas y sus partidarios, y especialmente la que tuvo lugar en Toeplitz, a finales de 1835. Antes de su celebración se hacían especulaciones sobre ayudas materiales y un posible reconocimiento. Así lo expresaba la prensa conservadora francesa y las mismas opiniones se repetían en los medios carlistas:

«On assure que Charles V sera reconnu aux prochaines conférences des souveraines du nord. (...) En reconnaissant don Carlos, les cabinets unis démontreront que leur politique expectante ne va pas jusqu'à l'abandon de leurs véritables intérêts» 21 .

La diplomacia sarda concedía también gran importancia a las decisiones que se pudiesen adoptar ${ }^{22}$. Mientras que don Carlos aspiraba a lograr que las Potencias pusiesen freno a las ayudas que Francia e Inglaterra proporcionaban a los liberales ${ }^{23}$.

En dicha reunión se pasó revista a las cuestiones de alta política y a la «situation général des choses», y en ellas destacaba lo que Metternich denominaba los «affaires spéciales» ${ }^{24}$. Entre éstos se encontraban la de Oriente, la holando-belga y la española.

El 2 de octubre se aprobaron los documentos en los que se resumían los resultados de la reunión, entre los que se encontraba el titulado "Affaires d'Espagne. Mémorandum arrêté en commun par les trois Cabinets alliés à

20 A.S.M.A.E. S.S. Sardegna Ambasciata Vienna 58. Borrador del despacho del Conde Sambuy (28.08.1835 n ${ }^{\circ}$ 50) al Conde Solaro. A.M.R.E. C.P. Sardaigne 307, fol. 30. Despacho del Embajador francés en Turín (24.10.1835 nº 112) al M.A.E.

${ }^{21}$ La Gazette de France 23.07.1835 (2/1). Un testimonio similar en A.H.N. Estado 8143; $6973^{2}$. Despacho del Cónsul en Bayona (30.09.1835) al MAE: «Sin embargo cuentan con que en el congreso de Toeplitz van a pronunciarse categóricamente reconociendo al Pretendiente como Rey de España, entonces añade Ozores, hay que decir se destruirá de suyo el Gobierno de Cristina».

${ }_{22}$ A.S.M.A.E. S.S. Sardegna R.P.Ch. 6. Anexo al despacho del M.A.E. (17.08.1835 no 136 bis) al Chevalier de Saint Marsan, Embajador sardo en Viena. "À Toeplitz on doit traiter des affaires de la Péninsule et il nous importe d'être informé de toutes les résolutions qu'on y prendra».

23 A.S.M.A.E. S.S. Sardegna Ambasciata Viena 58. Despacho del Embajador sardo en Viena (18.08.1835 $\left.\mathrm{n}^{\circ} 48\right)$ al M.A.E.

${ }^{24}$ H.H.St.A. G.A. Turín 23. Copia de la carta de Metternich (12.10.1835) al Conde Appony. El mismo texto en Metternich. Mémoires; vol. VI, p. 89-92. 
Toeplitz le 2 Octobre $1835 »^{25}$. El texto estaba dedicado más a la postura de las denominadas Potencias Marítimas (Francia e Inglaterra) y a su actitud respecto a la cuestión española, que a la situación interna de España. En algunos medios se atribuía la autoría del texto a Nesselrode «de concerto col Ministro Spagnolo Páez de la Cadena», lo cual no coincide con el papel que jugaba Metternich en dichas cuestiones y con la indiferencia mostrada por la diplomacia rusa respecto a España ${ }^{26}$.

Se iniciaba con una afirmación tajante: la cuestión española causaba un profundo pesar y movía a una seria meditación.

Tras este preámbulo se señalaba, lo cual no podía menos que contrariar a los carlistas, que se habían mostrado neutrales en la disputa sobre los derechos entre don Carlos y doña Isabel. Esta neutralidad entre ambos contendientes les llevaba a rechazar «le droit d'intervenir directement dans une affaire de succession contestée qui n'appartient qu'à l'Espagne seule». Esta actitud de las Potencias había condicionado las decisiones de Francia e Inglaterra, que no se habían atrevido a adoptar un mayor compromiso, pues en su opinión el reclutamiento de las legiones francesa e inglesa no podía ser interpretado como una intervención.

A continuación se esforzaba en minimizar la importancia de dichas tropas, argumentando que no se habían alcanzado las expectativas sobre la calidad y número de sus integrantes; que la falta de decisión y las dudas sobre su apoyo a Isabel II había desacreditado a ambas naciones ante los liberales europeos, y había evidenciado la inutilidad de la Cuádruple Alianza. En consecuencia, todo ello había perjudicado la causa de la Reina al incrementar las exigencias de los sectores más radicales y los partidarios de don Carlos. Tras estas apreciaciones se señalaba:

«L'intervention indirecte de la France et de l'Angleterre amène par conséquent aujourd'hui un résultat entièrement opposé à celui qu'elle était destinée à atteindre. Au lieu de faire preuve de courage et de force, les Puissances maritimes trahissent le secret de leur insuffisance, de leur faiblesse. Au lieu de rétablir, dans le Nord de l'Espagne, l'ordre et le repos, elles répandent sur la Péninsule tout entière le fléau de la guerre civile. Au lieu d'affermir le trône de la Reine, leur alliée,

${ }^{25}$ H.H.St.A. G.A. Turín 23. El texto del documento está anejo al despacho reservado de Metternich (17.10.1835) al Conde de Bombelles, Embajador austriaco en Turín. Las tesis del documento están también en el despacho del Nuncio en Viena (30.10.1835 n $\left.{ }^{\circ} 437\right)$ al Secretario de Estado Vaticano, en Franco Díaz de Cerio Informes y noticias de los nuncios en Viena, París y Lisboa sobre la España del siglo XIX (1814-1846). Tomo I: Los Nuncios en Viena.- Roma : Instituto Español de Historia Eclesiástica, 1990; p. 79

${ }^{26}$ A.S.V. S.S. Esteri R. 247 B. 407 . Despacho del Nuncio en Viena (13.10.1835 no 427) al Secretario de Estado Vaticano. El mismo texto en Franco Díaz de Cerio Los Nuncios en Viena p. 7879. La versión contrastaba con otras informaciones que acompañaba en la misma carta: Según el nuncio Metternich y Ancillon intentaron convencer al Zar para que diera dinero a don Carlos, pero que había respondido que a los amigos se les ayudaba con tropas, no con dinero. 
elles en précipitent la chute. Au lieu de combattre D. Carlos, elles ramènent à Madrid la Constitution de l'an 1812»27.

Después trazaban una visión apocalíptica de la situación española: caos absoluto sin que existan previsiones de una solución razonable. A pesar de que optaban por el mantenimiento de una política de expectativa, si no variaban las actuales condiciones, se plantearon la necesidad de prever el posible desarrollo de los hechos.

En el caso de que don Carlos se viese obligado a abandonar España, no se procedería de forma inmediata al reconocimiento de Isabel II, en tanto no se ofreciesen «à l'Europe monarchique assez de garanties morales pour qu'il soit permis aux Puissances du continent de se rapprocher de nouveau du Cabinet de Madrid». Asimismo se discutió sobre una posible subida al poder de los elementos más radicales, en cuyo caso se optaría por la inmediata salida de los diplomáticos acreditados en Madrid, y la expulsión de los representantes españoles en las tres Cortes.

La última previsión manejada era el posible triunfo de don Carlos, tras el cual los diplomáticos de las tres Cortes residentes en París informarían a Luis Felipe de la decisión de reconocer a don Carlos y le invitarían a unirse a su decisión, ya que la caída de Isabel II le liberaba de sus acuerdos y promesas de apoyar su causa. Y le señalarían que en bien de sus intereses y los de Francia, le interesaba mantener buenas relaciones con el nuevo Soberano español, vecindad que le resultaría más tranquilizadora que la de los radicales que marginarían a Isabel II.

Finalmente las Cortes Conservadoras señalaban que influirían en Madrid para que el restablecimiento de don Carlos «ne portât aucune atteinte au repos de la France, ni a la stabilité du gouvernement qui la régit».

Todas estas iniciativas se reducirían exclusivamente al ámbito francés, ya que sólo reconocían a este país un derecho de influencia sobre los acontecimientos de España, y de esta forma se le podría alejar de su política de acuerdos con Inglaterra.

Sin embargo no se adoptaron decisiones que modificaran la línea de comportamiento que se había llevado hasta ese momento. Es decir, no se produciría el reconocimiento de don Carlos por parte de dichas potencias. Respecto a la posibilidad de entregar ciertas cantidades, el Zar ruso se oponía porque consideraba que o se realizaba un apoyo total o no se podía admitir esta política de parcheo. El testimonio del Nuncio en Viena es bien expresivo al respecto:

«Sulla Spagna i Sovrani veggono finora una questione interna, che non spetta ad essi di decidere. Sono pero di accordo nel vedere nel partito di D. Carlo il partito conservatore, e nel partito della regina il partito rivoluzionario» 28 .

${ }_{27}$ H.H.St.A. G.A. Turín 23. «Affaires d'Espagne. Mémorandum arrêté en commun par les trois Cabinets alliés à Toeplitz le 2 Octobre 1835».

${ }_{28}$ A.S.V. S.S. Esteri R. 247 B. 407 . Despacho del Nuncio en Viena (30.10.1835 n 437) al M.A.E. 
Sambuy, hacía una valoración muy negativa de los resultados de la reunión:

«De belles phrases, de grandes discours paraissent avoir été à peu près l'unique résultat de ce Congrès, à moins peut-être qu'on ne s'y soit décidé à fournir quelques secours pécuniaires à Don Carlos, ce qui pourrait bien être, quoique les personnes les mieux informés n'en sachent rien, parce que la Prusse s'étant plaint qu'on n'observait pas assez le secret sur ce qui s'était déjà fait à cet égard, on aura pu développer d'un plus grand mystère encore ce qu'on aura voulu faire de nouveau, si tant est qu'on ait fait quelque chose» 29 .

Sin duda alguna, los resultados de la reunión fueron más amplios que los consignados en esta memoria, ya que como veremos más adelante algunos países se vieron legitimados para ejercer ciertas presiones sobre el Pretendiente.

Las potencias que apoyaban la causa de don Carlos se mostraban preocupadas por la imagen oscurantista que proyectaba y la cerrazón que había demostrado frente a las sugerencias de sus protectores:

«Ne croyez pas que je voie le repos de l'Espagne dans le triomphe de don Carlos; il n'est point ainsi. Ce que j'y cherche, c'est la direction conservatrice du Gouvernement en opposition avec l'influence funeste d'une Reine au maillot et de sa mère, plus remarquable par l'exubérance de son temperérament que par des qualités vraiment sérieuses» 30 .

Estas mismas ideas ya habían sido repetidas en diversas ocasiones tanto a los carlistas que viajaban por Europa, como en las conversaciones mantenidas entre los Gobiernos que no habían reconocido a Isabel II. Las críticas más habituales eran la de carecer de un programa claro de actuación, que no causase temor a sus aliados, y de personas capaces de llevarlo a cabo ${ }^{31}$.

Las sugerencias realizadas hasta ese momento se pueden resumir en dos principios: no restablecer la Inquisición y una amnistía general, que para el Gobierno ruso debía ser "por categorías»32. Una información muy similar llegó también a través del Marqués de Labrador, representante carlista en París, quien relataba una entrevista mantenida con Werther, embajador prusiano en la capital francesa, el cual había asistido a la reunión de Toeplitz. En su opinión la falta de reconocimiento estaba motivada porque no sabían «qué sistema de go-

29 A.S.T. LL. MM. Austria 133. Despacho del Conde Sambuy, Embajador sardo en Viena (26.10.1835 confidencial K) al M.A.E.

${ }^{30}$ Metternich. Mémoires, documents et écrits divers laissés par le Prince de Metternich, Chancelier de Cour et d'État publiés par son fils le prince Richard de Metternich classés et réunis par M.A. Klinkowstroem.Paris : E. Plon et $\mathrm{C}^{\mathrm{ie}}$ Imprimeurs-editeurs, 1883; vol. VI, p. 145 ; 30 de avril de 1836.

31 A.S.T. Legazioni 1. Despacho particular Embajador sardo en la Haya (27.08.1835) a MAE. «J'ai eu hier un long entretien avec le Baron Verstolk, la conversation a naturellement roulé principalement sur les affaires d'Espagne. Il pensa comme le Comte D'Aglié et moi que la cause de D. Carlos a été servie jusqu'ici avec bien peu d'adresse...».

32 A.H.N. Estado 8125. Despacho del Embajador en París (8.10.1835 nº 38) al M.A.E. 
bierno se propone seguir, y temiendo que se derramen torrentes de sangre y que se restablezca la Inquisición, cuyo nombre hace erizar los cabellos no solo en Rusia y Prusia, países en que dominan el rito griego y la comunión protestante, sino en Austria, en Cerdeña, en Nápoles y en los demás Estados católicos» ${ }^{33}$.

Los mensajes debieron de llegar por diversos conductos, porque el Secretario de Estado carlista escribió a su diplomático más cualificado, el conde de Alcudia, lo siguiente:

«... estoy harto convencido que las dudas que se supone haberse ofrecido para el reconocimiento de S.M. carecen del sólido fundamento que necesitaban para restablecerlas de un modo tan positivo como se dice, pues los actos no interrumpidos de clemencia y magnanimidad del alma de S.M., la dulzura del orden con que rige estas provincias, la tranquilidad con que en ellas viven muchos y muchos comprometidos con el partido de la usurpación, mil y mil otras reflexiones hechas...»34.

Es evidente que las Cortes conservadoras no querían ser responsables de una posible dura represión en España, que podría radicalizar la situación en el país y provocar reacciones no deseadas en Europa, por ello habían sugerido a don Carlos:

«far qualche pubblicazione, la quale rassicuri la Francia sulle conseguenze che teme dal di lui trionfo in Spagna e che nel tempo stesso offra qualche garanzia contro le rigorose reazioni che spaventano gran numero di grandi propietari e commercianti compromessi contro la di lui causa per effetto della quadrupla alleanza e che offra altresì alle persone sagge l'assicurazione di voler dirigere l'amministrazione della monarchia spagnuola nella via di riformare i gravissimi abusi e disordini permanenti dopo la perdita delle colonie e nell'ultimo periodo del regnop di Ferdinando VII. Ho la certeza che il Gabinetto di Prussia siasi associato a quelle disposizioni dell'Austria e che siasi portata innanzi l'idea di suggerire a D. Carlo il ripristinare non so quali diritti e franchigie di amministrazione interna delle varie provincie di Spagna, ciò che sembra ad illuminati personaggi un eccellente mezzo per promovere oportune e ben calcolate riforme e pronto espediente politico per attaccare alla causa del Re legittimo il partito provinciale, supposto forte e respetabile, che reclama quelle franchigie»35.

33 A.R.A.H. 9/6728. Despacho de Pedro Gómez Labrador (17.11.1835 nº 88) al Secretario de Estado carlista. La misma información fue transmitida a Viena por el Secretario de estado carlista H.H.St.A. Spanien 175. Traduction d'une dépêche adressée à S.E. M. le Comte d'Alcudia du Quartier General d'Ognate en date du 24 Novembre 1835.

${ }_{34}$ A.R.A.H. 9/6746. Despacho del Secretario de Estado carlista (24.11.1835) al Conde de Alcudia.

35 Coniglio, Giuseppe (a cura di). Le relazioni diplomatiche fra il regno delle due Sicilie e il Regno di Prussia / I e II serie: 1814-1848. Volume Unico (15 marzo 1819 - 5 Ottobre 1847).- Roma : Istituto Storico Italiano per l'età moderna e contemporanea, 1977. Despacho reservadísimo del Barón Antonini, embajador napolitano en Berlín (8.12.1835 nº 175) al M.A.E. 
Al parecer en las conversaciones mantenidas durante la cumbre de Toeplitz, Austria había señalado la necesidad de dirigirse a don Carlos para proponerle una serie de medidas de contenido político, iniciativa respaldada por los demás asistentes. En los primeros días de la reunión Metternich había mantenido una reunión informal con varios de los asistentes, entre los que se encontraba el representante sardo:

«Pour ce qui regarde l'Espagne le Prince a été d'avis qu'il est presque impossible que le Gouvernement de la Reine se soutienne; que la banqueroute est pour ainsi dire inévitable, et que cet événement sera extrêmement favorable à D. Carlos. Il pense que la Reine s'est retiré à Saint Ildefonse pour pouvoir mieux qu'à Madrid se mettre en sûreté à l'occasion. Il a ensuite reconnu que la position de D. Carlos deviendra difficile lorsqu'il s'agira d'établir un gouvernement, et une administration qui soit en état de calmer les différents partis, et ne pas laisser prendre le dessus à un système de réaction qui éterniserait les haines, et les discordes. Une des personnes présentes observa que las Puissances du nord ayant refusé de reconnaître à D. Carlos pour Roi d'Espagne, ce qui lui eût procuré un grand appui moral, elles risquaient de s'être par là privée du droit de lui donner des conseils sur la conduite à tenir dans la suite. Le Prince coupât court la dessus en disant D. Carlos n'est pas un enfant et n'ignore pas ce que les Puissances ont fait pour se cause» 36 .

Según Solaro había sido la insistencia de Ancillon la que había puesto en marcha la iniciativa de enviar un mensaje a don Carlos ${ }^{37}$. Lo que sucedió a finales de octubre y se consideró oportuno que se llevase a cabo a través del rey Carlos Alberto, por la especial consideración que tenía hacia él don Carlos ${ }^{38}$.

\subsection{La mediación sarda: Paolo Cerruti.}

Waldburg-Truchsess, embajador prusiano en Turín, aprovechó una conversación con el monarca sardo en su despacho para exponerle el mensaje de su Gobierno $^{39}$. Carlos Alberto, quien había combatido en España durante la campaña de 1823 , se jactaba de tener un buen conocimiento del carácter de los españoles, quienes consideraba hacían poco caso de las proclamas.

36 A.S.T. LL.MM. Prusia 28. Despacho del Embajador sardo en Berlín desde Toeplitz (14.08.1836 $\left.\mathrm{n}^{\circ} 130\right)$ a MAE.

${ }_{37}$ A.S.M.A.E. S.S. Sardegna R.P.Ch. 6. Anexo al despacho de Solaro (25.01.1836 no 3119) al Conde de Sales, Embajador sardo en París.

38 Stern, Alfred. «Documentos de historia española moderna II. Un informe del Conde de Waldburg-Truchsess, Ministro de Prusia en Turín, relativo a D. Carlos de 14 de noviembre de 1835».- En : Cultura española.- (noviembre 1907), p. 925-929. En este informe se señala que las instrucciones de Ancillon tenían fecha de 23 octubre.

39 Stern, Alfred. Op. cit. p. 926. A.S.M.A.E. S.S. Sardegna R.P.Ch. 6. Anexo al despacho de Solaro (25.01.1836 $\mathrm{n}^{\circ}$ 3119) al Conde de Sales, Embajador sardo en París. Solaro dice que Waldburg-Truchsess «ayant insisté beaucoup pour cette affaire». 
En su opinión la sangre árabe que corría por las venas de los españoles era la responsable de su carácter vengativo y cruel, y su idea de la justicia está dominada por la severidad sin que pueda ser atemperada por consideraciones políticas o estadísticas. Esta situación se ve agravada por la inexistencia de un tercer estado fuerte, tal como sucede en otros países, pues entre la nobleza y el pueblo sólo encontramos el clero, interesado en el mantenimiento de su posición de dominio sobre los otros dos grupos.

El silencio sobre planes de reformas políticas era una de las bazas de don Carlos para mantener junto a él a sus más celosos partidarios, cuyos sacrificios resultaban fundamentales en la guerra actual. Carlos Alberto consideraba que los seguidores de don Carlos no aspiraban a más recompensa que la esperanza de que «les ennemis de la patrie, les négros, comme ils les appellent seront punis et exterminés, et aux cris: Vive le Roi! ils joignent toujours des cris de mort» ${ }^{40}$; por ello cualquier insinuación de una amnistía provocaría fuertes disensiones en la filas carlistas. En su opinión don Carlos, a quien consideraba sabio, dulce y humano, no se dejaría llevar por tales sentimientos, y estaba seguro de que una vez asentado en el trono realizaría ciertas reformas.

A continuación Carlos Alberto entró a examinar el desarrollo de la guerra, sobre la que tenía una visión no excesivamente halagüeña. En primer lugar indicaba que don Carlos carecía de formación militar, por lo que no estaba en condiciones de dirigir las tropas ni habituado a los sufrimientos de la campaña; sin embargo su coraje le permití superar estas carencias. Desde el punto de vista material, consideraba que se estaba próximo al agotamiento de los territorios en los que se hallaban asentados, por lo que era preciso ocupar nuevas tierras, empresa para la que se necesitaba algo más que bravura. Cabía esperar un cambio de coyuntura si tenían éxito las iniciativas puestas en marcha en Cataluña y Aragón, a donde se debería enviar dinero.

Waldburg-Truchsess difería de Carlos Alberto en la valoración que hacía de la ayuda pecuniaria, que para él sería una consecuencia de la clarificación de los principios de gobierno que pensaba poner en marcha. Se mostraba de acuerdo en que una clarificación completa de los mismos podría perjudicar más que beneficiar, pero consideraba imprescindible y beneficioso mencionar la defensa y mantenimiento de las instituciones provinciales y el restablecimiento de las libertades civiles y locales.

Al finalizar la entrevista Carlos Alberto se comprometió a «transmettre ces conseils par une voie sûre à son royal ami, et qu'il l'engagerait vivement à les suivre» ${ }^{41}$.

40 Stern, Alfred. Op. cit. p. 927.

${ }^{41}$ Stern, Alfred. Op. cit. p. 928. A.S.M.A.E. S.S. Sardegna R.P.Ch. 6. Anexo al despacho de Solaro (25.01.1836 $\mathrm{n}^{\circ}$ 3119) al Conde de Sales, Embajador sardo en París. Solaro en este y otros escritos habla con un cierto distanciamiento de la misión señalando que se accedió «par pure condescendance au Gouvernement prussien et de son côté il n'a donné aucune mission à Mr. Cerruti». 
Este intercambio de opiniones se completó con una entrevista con el Conde Solaro, quien el 9 de noviembre de 1835 solicitó del Embajador prusiano en Turín, Conde de Waldburg-Truchsess, el envío de una memoria en la que se contuviesen las ideas propuestas por su Gobierno, documento que fue remitido al día siguien$\mathrm{te}^{42}$. Solaro, excelente conocedor del personal político que rodeaba al Pretendiente, comentó con desánimo que don Carlos carecía de colaboradores capaces de poner en ejecución los consejos que se le diesen, razón por la que iba a añadir a la propuesta prusiana la sugerencia de que debería tratar de llamar a su Corte alguna persona con capacidad, y ponía como ejemplo al Conde de Alcudia.

Dicho texto es un resumen del despacho cifrado de Ancillon, cuya redacción había sido modificada para no poner en peligro el sistema de cifra. El párrafo inicial resumía perfectamente el contenido de la propuesta:

«Plus nous nous intéressons au succès de la glorieuse et courageuse entreprise de l'Infant Don Carlos - plus nous regrettons que ce prince n'ait pas encore rompu le silence et présenté à la nation espagnole un drapeau sur lequel elle puisse lire son avenir en le reconnaissant comme son Roi. Dans l'époque où nous visons, plus que jamais la parole est devenu une puissance dont il faut se servir pour s'emparer et s'étayer de l'opinion publique» 43 .

La clarificación de la postura de don Carlos resultaría también útil de cara a luchar contra las falsedades, que están provocando la desconfianza y porque el silencio podría ser interpretado como una confirmación de los rumores.

A continuación se detallaban los puntos que debería contener el programa político de don Carlos:

a) Declaración de que su sistema político no iba a estar basado en el despotismo, sino en principios sólidos, inspirados por su paternal solicitud que siempre busca el bien de sus súbditos.

b) La firme resolución de mantener y reconstruir en su Reino las antiguas instituciones provinciales, declaración que incrementaría notablemente la adhesión de sus tropas y de sus partidarios.

c) Confirmar o devolver a las provincias los Fueros y privilegios que les son tan queridos, mantener o reconstruir en todos los lugares las libertades civiles y locales fundadas en la naturaleza y consagradas por la historia, libertades que resultan más convenientes a los pueblos que ese simulacro de libertad popular, que no produce sino anarquía y desorden; y que difieren notablemente de esa manía centralizadora que lo nivela todo y pisotea los derechos adquiridos de las naciones.

42 A.S.T. M.D.S.T. Cartella 3. Despacho del Embajador prusiano en Turín, Conde de Waldburg-Truchsess (10.11.1835) al Conde Solaro.

43 A.S.T. M.D.S.T. Cartella 3. 
d) Propuesta de reformas de una administración que a consecuencia de la pérdida de los territorios americanos carecía de una de sus principales bases.

El Gabinete prusiano consideraba que mediante una acción de este tipo se pondría fin a los rumores que estaban causando tantos males y se facilitaría el fin de la guerra.

Las propuestas estaban inspiradas en los principios contrarrevolucionarios, especialmente los defendidos en los países germánicos. En el texto nos encontramos con la propuesta de Herder del principio de desigualdad de los hombres, en contra de las tesis de los racionalistas; las ideas de Ernest Brandes sobre las creencias tradicionales, el apego a lo existente y el respeto del pasado en sí mismo; las posiciones de Auguste-Guillaume Rehberg en contra del igualitarismo, propuesto por los racionalistas.

Pero al mismo tiempo se optaba por la necesidad de realizar cambios, en consonancia con ciertas posiciones defendidas en sus primeros escritos por Brandes o por Rehberg.

A pesar de que al embajador prusiano se le manifestó que la iniciativa había sido acogida muy favorablemente por el monarca sardo, en documentos internos se mostraba reticente hacia la misma: «... la Prusse en particulier nous a fait dernièrement des ouvertures que le Roi n'a accueillies que avec la plus grande réserve et sans prendre le moindre engagement qui pût nous compromettre» ${ }^{4}$.

Para llevar a cabo esta misión se escogió a Paolo Cerruti quien había estado al frente del Consulado de Cerdeña en Málaga hasta finales de 1833, fecha en que se le destinó a Mahón. Al año siguiente se le encomendó la misión de actuar de enlace con los carlistas y de gestionar el envío de la ayuda (armas y dinero) destinada a su ejército. A principios de 1835 le encontramos en Bayona desde donde escribe que «l'affaire de Catalogne est pour le moment en suspens, parce que on attend des ordres de Don Carlos qui est déterminé d'y envoyer un général distingué et de toute sa confiance» ${ }^{45}$. Dos meses más tarde lo encontramos de regreso en Turín.

Esta opinión poco favorable no parece tan patente en las instrucciones que con fecha 15 de noviembre de 1835 le fueron entregadas a Cerruti, en las que se copia textualmente las notas entregadas por el Embajador prusiano ${ }^{46}$.

${ }_{44}$ A.S.T. LL.MM. Francia 303. Despacho confidencial y secreto del Conde Solaro (12.12.1835) al Conde Sales, Embajador sardo en París.

45 A.S.T. M.D.S.T. Cartella 3. Despacho de Paolo Cerruti (9.01.1835) al MAE. Roselli, Nello. Inghilterra e regno di Sardegna dal 1815 al 1847 / a cura di Paolo Treves, introduzione di Walter Maturi.- Torino : Giulio Einaudi editori, 1954; p. 601-602.

46 «Instructions données par M. le comte Solar de la Marguerite a monsieur le chevalier Cerruti à l'occasion de sa mission auprès de don Carlos en Espagne».- En : Bianchi, Nicomede. Storia documentata della diplomazia europea in Italia dall'anno 1814 all'anno 1861 / vol. IV. anni 18301846 (continuazione).- Torino : Unione Tipografico-editrice, 1867; p. 335-339. Roselli, Nello. Op. 
Se le ordenaba dirigirse a territorio carlista con toda la prudencia y el secreto conveniente, a fin de que ni el Gobierno francés ni el inglés puedan tener noticia alguna de su misión. Esta misma discreción debe observar en el propio Cuartel Real carlista, en el cual se le aconsejaba restringir los contactos al mínimo imprescindible.

Tras transcribir el documento prusiano Solaro añadía un largo texto que cambiaba parcialmente el sentido de la misión. Mientras que para los prusianos se trataba de una cuestión destinada al consumo interno, en las instrucciones se ampliaba notablemente el sentido de las declaraciones solicitadas a don Carlos:

«Toutes les Cours d'Europe déplorent l'affreuse lutte engagée en Espagne, et elles ne peuvent pas à moins de réfléchir que l'origine de cette lutte est attachée à un point de droit contesté qu'il ne leur appartient pas de décider. Pourquoi don Carlos ne publierait-il pas à l'Europe entière, par un manifeste signé par luimême, les fondements sur lesquels repose son droit exclusif au trône de l'Espagne? Pourquoi ne ferait-il pas un appel à toutes les Puissances donnant en même temps l'assurance des vues de modération avec lesquelles il monte sur le trône, et du désir exclusif qu'il a de faire le bonheur de l'Espagne? La parole royale serait une garantie pour toute l'Europe, et cette démarche engagerait plus spécialement tous les Cabinets, auxquels on ne s'est jamais adressés d'une manière officielle, à prendre à cœur ses intérêts» 47 .

Tras esta introducción se enumeraban una serie de medidas que deberían ser adoptadas para lograr el objetivo propuesto:

a) Llamar a una personalidad de prestigio tanto por su posición social como por los principios que ha profesado hasta el momento, ya que de esta forma se ganaría la confianza de todos. Se mencionaba expresamente el nombre del Conde de Alcudia. El objetivo fundamental de esta elección era poner orden entre los distintos cabecillas carlistas, cuya principal ocupación parecía la intriga permanente.

b) Se le exigía asimismo una modificación de las relaciones con Francia e Inglaterra. Debería olvidarse de su actuación en favor de Isabel II y adoptar una actitud más política. Y en concreto aconsejaba una mayor moderación en el lenguaje empleado por la prensa carlista al hablar de tales Gobiernos, pues la continuación de esta actitud dificultaría el establecimiento de relaciones una vez finalizada la guerra. En el caso de Inglaterra las líneas maestras de su política están dominadas por sus intereses materiales, y consideraban que establecería relaciones con don Carlos en el momento en que viese la posibilidad de encontrar ventajas en ello. Respecto a Francia eran de la opinión que su Monarca tenía un alto inte-

\footnotetext{
cit. p. 647 y ss.

47 Bianchi, Nicomede. Op. Cit. P. 337.
} 
rés en que en España no triunfasen los movimientos democráticos y republicanos a los que temía mucho más que al carlismo.

c) En la declaración debería incluir una mención a la Inquisición, asegurando que en ningún caso sería restablecida. Solaro indicaba que se trataba de salir al paso de ciertas calumnias puestas en circulación por enemigos de la causa, pero añadía al mismo tiempo que se trataba de un tema muy sensible, que incluso es manejado de forma poco adecuada por los partidarios. El restablecimiento de la Inquisición se asociaba a la existencia de un sistema de reacción y persecución, por lo que don Carlos debería anunciar que no pensaba utilizar medios extraordinarios para el mantenimiento del trono.

La cuestión de la Inquisición estaba íntimamente unida al carlismo por la opinión pública, que identificaba reacción absolutista e Inquisición sin que existiese una base en la que fundamentar dicha idea. La Inquisición que fue abolida por las Cortes de Cádiz quedó repuesta en todas sus funciones por el decreto de 4 de mayo de 1814, sin embargo Fernando VII no la restauró tras su vuelta al ejercicio del poder absoluto en 1823 , a pesar de las numerosas presiones que ejercieron desde los medios eclesiásticos ${ }^{48}$. Villiers señala que los liberales indicaban que no estaban dispuestos a tolerar el triunfo de los principios carlistas y de la Inquisición ${ }^{49}$.

Solaro hacía finalmente un llamamiento a la responsabilidad de don Carlos, quien debería actuar como un estadista, a fin de que su actitud no perjudicase el éxito de su causa:

«Vous prierez don Carlos à prendre en mûre considération ces réflexions, et vous lui direz que n'étant pas possible de mieux remplir qu'il ne le fait la glorieuse tâche qu'il s'est imposée, de soutenir l'épée à la main ses droits imprescriptibles à la couronne, il serait encore plus admirable si son attitude comme chef d'un État devenait également conforme à la gravité des circonstances et des chances qu'il a à courir, et empêcher ainsi que les lauriers acquis par tant de sang généreux ne deviennent stériles par faute de cette conduite politique dans tous les temps, et spécialement dans les nôtres, aussi nécessaire que le courage personnel dont il donne tant d'exemple»50.

Un consejo similar se le hacía al hablar de la Inquisición, punto en el que se le recordaba que, incluso teniendo en cuenta las brutalidades de los liberales y

\footnotetext{
48 Ministerio de Relaciones con las Cortes y de la Secretaría del Gobierno. Actas del Consejo de Ministros.- Madrid : Ministerio de Relaciones con las Cortes y de la Secretaría del Gobierno, 1989; tomo I; sesión $\mathrm{n}^{\circ} 80(12.05 .1825)$ en la que se discute sobre la creación de Juntas de Fe por el Arzobispo de Tarragona para tratar los asuntos que antes juzgaba el Tribunal de la Inquisición; sesión $\mathrm{n}^{0} 114$ (31.07.1825) en la que se plantea una situación similar en la diócesis de Orihuela.

49 Bullen, Roger. Op. Cit. p. 117. Despacho privado de Villiers (16.03.1834) a Palmerston.

${ }^{50}$ Bianchi, Nicomede. Op. Cit. P. 338.
} 
en consecuencia la sed de represalias de sus partidarios, debería evitar dar argumentos a sus enemigos y fundar su sistema de gobierno en principios de justicia y no en el ejercicio del terror.

Finalizada la enumeración de los mensajes que debería transmitir a don Carlos se le encomendaba informar sobre la opinión de don Carlos en relación con dichos puntos, y además remitir noticias exactas de las siguientes cuestiones:

a) Situación del Ejército (número de la fuerza, medios materiales y recursos que tenía a su disposición)

b) Listado de las personas que rodean a don Carlos y ascendiente que tienen sobre él.

c) Situación interior de la Corte

d) Espíritu de los pueblos que se hallan bajo su gobierno

e) Situación de las tropas que le van a llevar a Madrid.

f) Situación de los contactos con personalidades que apoyan a la Reina, y si se les ha tratado a atraer a su campo.

En este último punto trataba de salir al paso de las objeciones planteadas en diversas ocasiones por los carlistas. No se debía despreciar este sistema de acuerdos, que en opinión de algunos carlistas suponían compromisos y concesiones personales peligrosas, pues, cuando el objetivo es la finalización de una guerra civil tan horrible, se deben usar todos los medios para atraer a muchas personas a las que sólo el miedo les impide cambiar de bando.

Se aconsejaba a Cerruti una especial delicadeza en sus conversaciones para evitar que su presencia pudiera ser interpretada como una intromisión, y además debería tener en cuenta la especial situación de aquellas personas que, inmersas en una situación tan dura, pudieran ser poco propicias a consejos de moderación.

Solaro preveía también la posible respuesta carlista de que para finalizar la guerra en lugar de consejos necesitaban más medios materiales y el reconocimiento público de sus derechos. La contestación a la primera objeción resultaba fácil ya que Cerdeña y Prusia se habían destacado en las aportaciones de ayuda, actitud que pensaban continuar en la medida de sus posibilidades. La actual iniciativa era el medio más seguro para facilitar la victoria y el reconocimiento de sus derechos.

Pocos días más tarde Solaro daba cuenta al Embajador prusiano del envío del emisario, cuyo nombre no se citaba, y en la misma comunicación se adjuntaba una copia de las instrucciones ${ }^{51}$. Ancillon comunicó inmediatamente la información a diferentes diplomáticos, entre los que se contaba el representante

51 A.S.T. M.D.S.T. Cartella 3. Despacho del Conde Solaro (20.11.1835) al Embajador prusiano en Turín, Conde de Waldburg-Truchsess. 
napolitano, Barón de Antonini ${ }^{52}$. El secreto de la misión encomendada a Cerruti no permaneció largo tiempo. Aunque no se tenían informaciones muy exactas circulaba el rumor de que había sido nombrado Cónsul en Barcelona, pero que antes de hacerse cargo de su puesto se le había encomendado dirigirse al Cuartel de don Carlos ${ }^{53}$.

Como el Gobierno Sardo estaba en ese momento terminando la negociación de un acuerdo con Portugal, del cual era garante el Gobierno Británico, trató de desmentir esta información ante el Embajador inglés. Para que sus palabras fuesen más creíbles le informó al mismo tiempo de la negativa a conceder permiso a la Princesa de Beira para regresar a Turín ${ }^{54}$.

Quadrado acudió a pedir explicaciones a Solaro, quien anteriormente le había asegurado que no se nombrarían nuevos cónsules. En opinión del diplomático español le había «sorprendido estuviese enterado del asunto», le explicó que se pensaba nombrarle aunque no ejerciese hasta que se produjese el reconocimiento y aseguró desconocer lo del posible viaje al Cuartel Real carlista ${ }^{55}$.

El 26 de noviembre el emisario sardo salía de Niza. El 12 de diciembre había llegado ya a Burdeos y cinco días más tarde a Vera del Bidasoa, desde donde escribió al Secretario de Estado carlista indicándole que iba a dirigirse a Oñate, en donde «yo tomaré otro nombre ... a fin de que nadie sepa quién soy, ni el motivo porque he venido» ${ }^{56}$. El día de Navidad escribía desde el Cuartel Real, aunque no había logrado ver al Pretendiente. La llegada de Cerruti hizo pensar a los carlistas que venía nuevamente a traer dinero, de cuya falta se quejaban amargamente, y se recordaba la promesa que se les había hecho, el año anterior, de entregarle 10.000 francos $^{57}$.

52 Coniglio, Giuseppe (a cura di). Op. Cit. p. 232-233. Despacho del Barón Antonini, embajador napolitano en Berlín (8.12.1835 no 174) al M.A.E.

53 A.M.R.E. C.P. Sardaigne 307, fol. 178. Despacho del Embajador francés en Turín (28.01.1836 $\mathrm{n}^{\circ}$ 27) al M.A.E. El Embajador dice que en vista de que había circulado la noticia de que se dirigía a ver a don Carlos, se había anulado su nombramiento para Barcelona. Según él, ello y el haber impedido el viaje de la Princesa de Beira a Cerdeña demostraban la imparcialidad sarda. Un resumen de la misión en A.S.T. M.D.S.T. 3. Copie d'un rapport présentée à S. E. Monsieur le Comte Solaro de la Marguerite, Ministre des Affaires Etrangères de S.M. le Roi de Sardaigne, sur l'état de l'armée de D. Carlos, etc. A.H.N. Estado 5727. Despacho del Encargado de Negocios español en Turín (2.02.1836 $\left.\mathrm{n}^{\circ} 188\right)$ al M.A.E.

${ }^{54}$ P.R.O. F.O. 67, 96. Despacho de Foster $\left(28.01 .1836 \mathrm{n}^{\circ}\right.$ 8) a Palmerston. "The Sardinian Minister, at the same time, informed us, that a M. Cerutti, who was to succeed M. Ponti, as Consul of this Country at Barcelona, should no longer be destined to that Post, since it approved that M. Quadrado had some suspicion of his being a Carlist, and had for some time been questioning him as to a report of M. Cerutti having the intention of passing trough the lines of Don Carlos».

${ }_{55}$ A.H.N. Estado 5727. Despacho del Encargado de Negocios español en Turín (2.02.1836 n ${ }^{\circ}$ 188) al M.A.E.

56 A.R.A.H. 9/6743. Carta de Paolo Cerruti (18.12.1835) a Carlos Cruz Mayor.

57 A.S.T. M.D.S.T. Cartella 3. Despachos de Paolo Cerruti (26.11.1835; 12.12.1835; 17.12.1835; 24.12.1835) al Conde Solaro. 
El mismo día de su llegada se presentó ante Cruz Mayor, quien a continuación le llevó a presencia de don Carlos. Cerruti describía en términos muy elogiosos el recibimiento y a continuación daba cuenta de lo hablado, utilizando un lenguaje críptico:

«Elle [Cerruti] lui a exprimé ceux de sa Famille [Potencias conservadoras y Rey de Cerdeña] et lui a fait connaître tout l'étendue du véritable attachement [documento de Prusia], que de ce coté on a pour lui. Son ami [Carlos Cruz Mayor, Secretario de Estado carlista] a été on ne peut plus reconnaissant à la preuve manifeste de ces sentiments qu'on viennent de lui donner; Il a écouté tout ce, que le jeune personne [Cerruti] lui a dit, et il est parfaitement entré dans toutes les idées, qu'Elle lui a expliquées. Enfin, Elle en est contente au delà de tout ce qu'on peut s'imaginer, et Elle espère qu'Elle aura le bonheur de satisfaire à toute la Famille, qui l'a choisie pour être l'intermédiaire de ses sentiments auprès de son excellent ami» 58 .

Durante los siguientes días habló en diversas ocasiones con don Carlos, conversaciones en las que le explicó de forma más detallada «les réflexions contenues dans la communication de la Corte de Prusse», información que le entregó también por escrito junto con las instrucciones que había recibido ${ }^{59}$. El Pretendiente, una vez que lo hubo examinado, transmitió el documento a Cruz Mayor, encargándole preparar una respuesta.

Una semana más tarde Cerruti remitía un nuevo despacho que levantaba las alarmas sobre el éxito de la misión, señalando a Cruz Mayor como el responsable de la resistencia a la aceptación de las propuestas:

«La schall $n^{\circ} 348,37 ; 147,3$ que la jeune personne a porté a son ami, a été trouvé d'abord de bon goût et l'ami manifeste à la même, qu'il n'était pas éloigné de s'en servir en plusieurs choses pour modèle dans ses ateliers. Effectivement il le descendit ces jours-ci dans son comptoir pour le faire voir a son commis, et lui communiquer son idée; mais celui-ci, qui n'aime pas les modes étrangères, et qui tient beaucoup aux usages du pays, ne fut pas du même avis que son principal; il trouva que les couleurs et l'étoffe du Schall ne pouvaient pas convenir dans ce pays, et il persuada son principal à ne vouloir pas faire aucune innovation dans sa fabrique, parce que cela non seulement ne lui serait d'aucun avantage, mai qu'au contraire cela pourrait causer sa ruine; maintenant la jeune personne est fort embarrassée, ne sachant pas comment faire usage de son schall sans déplaire à son ami» ${ }^{60}$.

58 A.S.T. M.D.S.T. Cartella 3. Despacho de Paolo Cerruti (27.12.1835) al Conde Solaro. Las informaciones entre corchetes son interpretaciones del autor.

59 A.S.T. M.D.S.T. 3. Copie d'un rapport présentée à S. E. Monsieur le Comte Solaro de la Marguerite, Ministre des Affaires Etrangères de S.M. le Roi de Sardaigne, sur l'état de l'armée de D. Carlos, etc. p. 3.

${ }^{60}$ A.S.T. M.D.S.T. Cartella 3. Despacho de Paolo Cerruti (3.01.1836) al Conde Solaro. 
$\mathrm{Al}$ objeto de hacerle modificar de opinión mantuvo varias entrevistas para convencerle de la conveniencia de secundar la solicitud prusiana. La respuesta definitiva llegó a los pocos días, aunque deberían transcurrir dos meses para que quedara plasmada por escrito en un largo documento remitido a la Corte de Turín. Este retraso obligó a Cerruti a regresar a Turín, una vez acordado con Cruz Mayor en que le remitiría el texto tras su aprobación ${ }^{61}$.

La reacción ante la propuesta reforzaba la opinión de las Cortes Conservadoras y especialmente de Metternich, quien se había quejado en más de una ocasión de la pobreza intelectual y política de don Carlos y sus consejeros. La versión de Cerruti venía además a ahondar en la cuestión de la carencia de carácter de don Carlos, incapaz de asumir decisiones de gobierno, y siempre dominado por sus consejeros, a los que se achacaba una notable carencia de visión:

«La grande influence, que le Commis d'ici a auprès de son principal, laisse peu d'espoir a la jeune personne de pouvoir déterminer son ami a adopter pour ses ateliers quelqu'une des nouvelles méthodes de fabrication, dont Elle lui a apporté les modèles. Malgré toutes les réflexions, qu'Elle lui a faites sur les avantages immenses qu'il en retirerait, elle ne croit pas qu'on s'en servira, car le commis, sans l'intermédiaire ou l'avis du quel son ami ne fait jamais rien, s'y est vivement opposé, et il a persuadé son maître, que ces changements et ces innovations causeraient sa ruine» 62 .

Cerruti opinaba que la gestión podría haber tenido mayores posibilidades de éxito en caso de haber llegado con dinero para ayudar a la causa carlista, y achacaba a este motivo las reticencias de Cruz Mayor.

De acuerdo con las instrucciones recibidas, remitía informaciones sobre la «camarilla» que rodeaba a don Carlos, textos que proyectaban una imagen bastante negativa. El 26 de enero indicaba que tenía muchas cosas que contar y no todas agradables, para añadir a continuación: «Toutes les opérations restent sans bénéficie à cause des entraves, qu'elles rencontrent dans une concurrence occulte, qui prend là dessus, et qui bientôt s'emparera de toute la place» ${ }^{63}$.

Igualmente dio cuenta de las intrigas políticas que condujeron al cambio de ministerio. El 17 de enero, en un mensaje en clave, señalaba que las intrigas tenían un aspecto bastante serio y que en breve se produciría el cambio ministerial. A mediados de marzo se encontraba en Turín, aunque pocos meses más tarde regresaba, pues en agosto mencionaba las maquinaciones del Obispo de León para desbancar a Juan Bautista Erro Azpiroz del puesto de Ministro Uni-

${ }^{61}$ A.S.T. M.D.S.T. 3. Copie d'un rapport présentée à S. E. Monsieur le Comte Solaro de la Marguerite, Ministre des Affaires Etrangères de S.M. le Roi de Sardaigne, sur l'état de l'armée de D. Carlos, etc. p. 4. Dice que tiene noticias de que ya ha sido enviado.

62 A.S.T. M.D.S.T. Cartella 3. Despacho de Paolo Cerruti (12.01.1836 n $\left.{ }^{\circ} 12\right)$ al Conde Solaro.

${ }_{63}$ A.S.T. M.D.S.T. Cartella 3. Despacho de Paolo Cerruti (26.01.1836) al Conde Solaro. 
versal ${ }^{64}$. El fracaso de la misión de Cerruti no facilitó que se mantuviese la imagen de ineficacia y oscurantismo que la causa carlista tenía incluso entre los Gobiernos que les apoyaban. Solaro refleja así su pesimismo sobre la evolución de los acontecimientos en un momento en que los cambios políticos del Gobierno de Mendizábal podían traducirse en un gran apoyo a los sublevados:

«Malheureusement des grandes intrigues sortent autour du magnanime D. Carlos, ces intrigues, plus que tout autre chose s'opposent au succès de sa cause et aux progrès de ses armes» 65 .

Dado que la misión había pasado a ser casi de dominio público, Solaro trató de proteger a Cerruti enviando instrucciones al Conde de Sales, embajador sardo en París, a fin de que estuviese informado del objeto de la misión, "qu'elle ne se rapportait à aucune idée ou promesse de secours d'aucun genre» y mediase ante las autoridades francesas si detenía al diplomático sardo ${ }^{66}$.

Fracasada la gestión, Solaro esperaba que la llegada al Cuartel Real de Juan Bautista Erro ayudase a mejorar la situación en que se encontraban los carlistas $^{67}$. En su opinión el celo no era suficiente, pues se necesitaba también capacidad y actividad.

\subsection{Los informes de Paolo Cerruti.}

La misión de don Carlos tenía un doble objetivo: transmitir las propuestas realizadas por Prusia y recoger información sobre la situación de la causa carlista. Al objeto de cumplir con ésta última instrucción Cerruti entregó a sus superiores un informe de 16 páginas "Copie d'un rapport présentée à S. E. Monsieur le Comte Solaro de la Marguerite, Ministre des Affaires Etrangères de S.M. le Roi de Sardaigne, sur l'état de l'armée de D. Carlos, etc.», fechado en Turín el 12 de marzo de $1836^{68}$. En el último párrafo anunciaba un segundo informe sobre las personas que integraban la Corte carlista.

${ }^{6}$ A.S.T. M.D.S.T. Cartella 3. Despachos de Paolo Cerruti (17.01.1836; 3.08.1836) al Conde Solaro. A.S.T. LL.MM. Francia 304. Despacho (Gabinete particular) del Conde Solaro (17.05.1836) al Conde de Sales, Embajador sardo en París.

65 A.S.M.A.E. Ambasciata Vienna 57. Despacho confidencial del Conde Solaro (17.02.1836) al Conde Sambuy.

66 A.S.M.A.E. S.S. Sardegna R.P.Ch. 6. Anexo al despacho de Solaro (25.01.1836 n 3119$)$ al Conde de Sales, Embajador sardo en París.

${ }^{67}$ A.S.M.A.E. Ambasciata Vienna 57. Despacho del Conde Solaro (26.04.1836 n $\left.{ }^{\circ} 1346\right)$ al Conde Sambuy. «P.S. L'arrivée de Monsieur Erro au quartier Général de D. Carlos nous fait espérer que les affaires seront conduites avec plus d'activité, et même de capacité que jusqu'à présent, le zèle ne suffisant pas en des circonstances si graves et si difficiles sur tout ayant à lutter contre des ennemis si puissamment soutenus par l'or, les armes et les conseils de l'Angleterre».

68 A.S.T. M.D.S.T. 3. Copie d'un rapport présentée à S. E. Monsieur le Comte Solaro de la Marguerite, Ministre des Affaires Etrangères de S.M. le Roi de Sardaigne, sur l'état de l'armée de D. Carlos, etc. El documento lleva fecha de 12 de marzo de 1836. 
A pesar del título las informaciones se refieren a aspectos políticos importantes que es interesante señalar.

Sobre el Ejército proporciona datos estadísticos (36 batallones de infantería de unos 800 hombres, 12 escuadrones de caballería con entre 80 y 100 caballos); menciona los esfuerzos realizados para incrementar el número de soldados hasta alcanzar la cifra de 40.000 hombres, que quedarán organizados en un ejército de operaciones (20.000 hombres en las provincias del norte y 10.000 para las expediciones a Cataluña, Castilla y Asturias) y otro de reserva (10.000 hombres); considera que la caballería tiene problemas tanto para conseguir caballos como para disponer de un buen jefe.

Respecto a los jefes militares las informaciones se circunscriben a tres nombres. Sobre el general Eguía, en ese momento Comandante en jefe del Ejército carlista, decía que era un militar valioso, pero sus limitaciones físicas le impedían actuar efectivamente. A Bruno Villarreal lo califica de muy hábil y muy valiente, y señala que es el que asesta el golpe definitivo en las batallas; en su opinión sería un digno sucesor de Zumalacárregui. El tercer nombre sobresaliente es el de Rafael Maroto, quien está enfrentado a la «camarilla» y en particular al general Moreno, que ha conseguido alejarlo del mando. De los dos últimos dice que son los que tienen mayor predicamento entre las tropas. A estos nombres añade el de Iturralde, pero circunscribiendo su fama a las tropas navarras.

Sobre el equipo militar afirma que, en ese momento, las tropas estaban completamente uniformadas (capote gris claro y pantalón rojo) y armadas; y como curiosidad señala que no utilizan chacó sino que se ha generalizado la boina roja hasta en la oficialidad. La tela llega desde Francia en contrabando. Los fusiles provienen de los que capturan a los liberales y de los fabricados en la manufacturas de Eibar y Placencia, que suministran a un ritmo de 1.200 al mes, cifra que podría alcanzar los 5.000 en caso de tener dinero para pagar los sueldos de los armeros.

A continuación informa sobre el espíritu público tanto de las tropas como de la población civil, con anotaciones que resultan muy interesantes.

En primer lugar aseguraba que la moral de la tropa era excelente, y que su adhesión y constancia nadie cuestionaba, afirmación que nadie podía poner en duda dadas las penalidades que habían pasado anteriormente. Tras esta afirmación indicaba que los militares naturales de las cuatro provincias sólo aspiraban a defender los derechos de su rey, y una vez logrados se retirarían a sus casas.

Es necesario destacar su apreciación sobre el peso del factor foral en la génesis del levantamiento, especialmente por parte de una persona llegada como mensajero de una petición de mantenimiento de los fueros:

«'ai entendu fort peu de ces militaires parler des privilèges des leurs Provinces, et j'ai remarqué, que chez eux c'est un motif secondaire, et que la plupart d'eux ont pris les armes par suite de leurs sentiments pour le Roi, et parce qu'ils ont une sincère et profonde aversion pour les libéraux, et pour le gouvernement de la Reine. L'esprit des populations des dites Provinces est le même, et leurs sentiments sont décidément pour le Roi et pour la Religion. Les personnes cepen- 
dant, qui ont quelque influence dans le pays, tels que les propriétaires, les magistrats, les employés, etc. sont naturellement ceux, qui tiennent le plus aux privilèges, dont il est question, et qui sont vivement intéressés à les conserver. Les membres de leurs juntes respectives ne les perdent pas de vue non plus, et même quelque fois par leur trop grande susceptibilité ils causent des embarras au Roi, qui en éprouve les plus vifs chagrins» 69.

Del texto es necesario llamar la atención sobre varios hechos. En primer lugar la afirmación de que los fueros no tuvieron ningún peso en la génesis de la guerra, afirmación en la que coincide con varios testimonios coetáneos. Uno de los primeros testimonios en este sentido es el de Henningsen quien tras haber permanecido más de un año a las órdenes de Zumalacárregui decía: «Nos dicen que las provincias del Norte están luchando, no por don Carlos, sino por sus propios privilegios. Esto no es así: el realismo en los campesinos españoles es un sentimiento que no se concibe ahora fácilmente en el resto de Europa»70. La misma opinión manifiesta otro estrecho colaborador del general guipuzcoano, José Antonio Zaratiegui: «Un error bastante común ha inducido a creer que los navarros tomaron las armas a la muerte de Fernando VII, no más que por defender sus Fueros. (...) La guerra, comenzada en este país en 1833, no tuvo otro objeto que la defensa de los derechos del entonces infante don Carlos María Isidro a la corona de España.... $\gg^{71}$.

La versión de Cerruti coincide plenamente con la de estos autorizados protagonistas de aquella guerra. Cerruti presenta además una visión que coincide con análisis recientes sobre el papel de los fueros como un instrumento de dominio de ciertos grupos sociales.

Una parte del documento estaba dedicada a analizar la situación económica. En primer lugar se elogiaba los inmensos sacrificios realizados por las Provincias, que se encontraban casi exhaustas; y concluía insinuando que la guerra podría tener un final más rápido si se les proporcionaba recursos económicos, que era la principal carencia. Alababa la tranquilidad y seguridad existente en el territorio.

\subsection{La intervención del Barón Haber.}

A finales de diciembre de 1835 el embajador austriaco en París daba cuenta de una nueva iniciativa puesta en marcha por el Embajador prusiano en París.

${ }^{69}$ A.S.T. M.D.S.T. 3. Copie d'un rapport présentée à S. E. Monsieur le Comte Solaro de la Marguerite, Ministre des Affaires Etrangères de S.M. le Roi de Sardaigne, sur l'état de l'armée de D. Carlos, etc. p. 11.

${ }^{70}$ Henningsen, C.F. Campaña de doce meses en Navarra y las Provincias Vascongadas con el general Zumalacárregui.- Burgos : Editorial española, 1937, p. 9. El libro fue editado inicialmente el año 1836.

${ }^{71}$ Zaratiegui, J.A. Vida y hechos de Don Tomás de Zumalacárregui.- Madrid : SARPE, 1986, p. 12. La primera edición es de 1845. 
El emisario era el barón Maurice de Haber, quien había participado en la negociación de empréstitos carlistas, y que pensaba aprovechar dicha cuestión como excusa para acercarse a la Corte carlista ${ }^{72}$.

El Barón de Haber era un viejo conocido en los ambientes financieros y absolutistas europeos, aunque no era bien recibido por algunos gobiernos. En septiembre de 1833 el Embajador español en París se negó a darle pasaporte, aunque posteriormente se vio obligado a visarlo por venir expedido por el representante de Baden y con los visados del Ministerio de Asuntos Exteriores y de la Policía franceses ${ }^{73}$. Zea Bermúdez respondió que se había dado orden de impedirle la entrada, advirtiéndole que en adelante debía negarse a refrendar pasaportes de individuos sospechosos.

Durante el año 1834 Haber participó en la negociación de un empréstito para don Carlos, que finalmente acabó en una pelea con las autoridades carlistas. Resulta sorprendente que conociendo el enfrentamiento existente, del que la prensa publicó bastantes datos, se eligiese a tal persona para cumplir una misión tan delicada ${ }^{74}$. Incluso durante su permanencia en territorio carlista Joaquín Abarca, Obispo de León, envió una información criticando su proceder:

«No me es agradable importunar tanto la atención del Gobierno de S.M. con las publicaciones imprudentes del Barón Haber, pero habiendo en este día recibido la aprobación Real del empréstito que el Sr. D. Juan Bautista Erro y yo hemos contratado con Mr. Ouvrard, no puedo dispensarme de acompañar al adjunto artículo del Times por el contraste que forma su contenido con la resolución mencionada, es lo que aparece una nueva y convincente prueba de su desmesurado orgullo» 75 .

Por el despacho del Conde Appony parecía que se trataba de un ofrecimiento del financiero en el contexto de las conversaciones mantenidas con el embajador prusiano Barón de Werther, quien anteriormente había desempeñado puestos en la representación de su país en Madrid:

72 H.H.St.A. G.A. Paris 16 (original), Frankreich 297 (borrador). Despacho del Embajador austriaco en Paris (22.12.1835 $\left.\mathrm{n}^{\circ} 66 \mathrm{~A}\right)$ a Metternich. La carta de Saint Simon a Haber tenía fecha de 27 de diciembre [A.R.A.H. 9/6726].

73 A.H.N. Estado 5296. Despacho del Embajador español en París (31.10.1833 no 772) al M.A.E; y su respuesta de 8 de noviembre.

${ }^{74}$ Los pormenores de su relación financiera con los carlistas en estas fechas pueden verse en Urquijo Goitia, José Ramón. «Empréstitos y ayudas financieras en favor del Pretendiente carlista».En : Museo Tomás Zumalacárregui. Estudios históricos I.- Ormaiztegui : Diputación de Guipúzcoa, 1990; p. 107-127. Tras la ruptura de la relación Maurice Haber publicó una carta en el MorningHerald, que fue reproducida posteriormente en La Gazette de France 26.04.1835 (1/1). A.R.A.H. 9/6723. Despacho del Conde Almaida y del Vizconde de Canellas (12.09.1834) a don Carlos de Borbón. «Hemos dicho desde el principio muchas veces que el empréstito confiado al barón de Haber nada más produciría que descrédito, grandes pérdidas al Estado....».

75 B.N.P. Mss. Espagne 585, fol. 48. Despacho de Joaquín Abarca (20.02.1836) al Secretario de Estado carlista. 
«La correspondance officielle de Mr d'Ancillon avait fait connaître au Baron de Werther la manière dont cette importante question était envisagée par ce Ministre ; aussi est-ce sur les vœux exprimés à cet égard dans les dépêches de son Cabinet que Mr. le Envoyé de Prusse a basé le raisonnement dont il s'est servi envers Mr. de Haber en autorisant ce voyageur a, si l'occasion s'en présentait, le faire valoir auprès de l'Infant» ${ }^{76}$.

El Embajador austriaco había supervisado la iniciativa, a la que se había querido dar la menor solemnidad posible, por lo que el encargo fue realizado por un subordinado del embajador Werther, Mr. Brassier de Saint Simon, en ese momento al frente de la Legación en calidad de encargado de negocios, aunque Appony le transmitió que el contenido del mensaje contaba con la total aprobación por parte de su Gobierno. Los puntos que se le encargaba transmitir eran los siguientes:

a) Separar de forma absoluta la cuestión de la sucesión al trono de España de las de otros países, al objeto de convertirla en una causa nacional y puramente española. Si bien en el documento original no se hacía menciones específicas, en el despacho de Appony se ponía especial énfasis en la necesidad de distanciarse de los legitimistas franceses

b) Conservación o restablecimiento de las instituciones provinciales, que, lejos de ser incompatibles con el principio monárquico, son su más firme apoyo.

c) Declaración clara y positiva de que no se va a restablecer el tribunal de la Inquisición.

d) Amnistía, perdón y clemencia después de la victoria, en lugar de odio y venganza.

El texto de Appony finalizaba con una descripción bastante despectiva de la actividad de los legitimistas franceses y portugueses, a quienes alentaban los gobiernos de Nápoles y Módena, que deseaban fundir su causa con la de don Carlos. Y mezclaba en todas estas intrigas al Duque de Blacas, al Barón de Capelle y al financiero Ouvrard, quien estaba interesado en rentabilizar los bonos portugueses.

Las diferencias con las propuestas anteriores están, sin duda, determinadas por la mayor intervención austriaca y por el hecho de que el perfil definitivo del documento se hubiese gestado en París.

El primer punto obedece claramente al deseo de hacer más presentable a Luis Felipe la causa carlista, actividad en la que estaban trabajando los embaja-

${ }^{76}$ H.H.St.A. G.A. Paris 16 (original), Frankreich 297 (borrador). Despacho del Embajador austriaco en Paris (22.12.1835 $\left.\mathrm{n}^{\circ} 66 \mathrm{~A}\right)$ a Metternich. Una copia de las propuestas en A.S.T. LL.MM. Francia 262. Anexo al despacho del Embajador sardo en París (3.05.1836 no 1452) al Conde Solaro. Pirala Criado, Antonio. Vindicación del general Maroto y manifiesto razonado de las causas del Convenio de Vergara / Edición de Pedro Rújula.- Pamplona : Urgoiti, 2005; p. 60. 
dores de las Cortes Conservadoras acreditados en la capital francesa. Se trata de una propuesta mucho más radical que la introducida por Solaro en las instrucciones de Cerruti, pues se ha pasado de una petición de mejora de las relaciones con Francia e Inglaterra a un alejamiento respecto a las causas legitimistas de los países vecinos, con uno de los cuales (Portugal) tenía estrechas relaciones familiares. Para el Marqués de Labrador, representante carlista en París se trataba posiblemente de una insinuación realizada desde París:

«En seguida habló con gran empeño de las cuatro insinuaciones, o consejos, insistiendo particularmente en que era esencial para el triunfo del Rey nuestro Señor, que su causa se separase enteramente de la de Francia; y que además de otras razones don Carlos debía hacerlo por gratitud de haberse Luis Felipe resistido a la intervención. El Barón Werther habló sobre este punto con tanto fuego e insistió con tal tenacidad en repetir que para el triunfo de S.M. era necesario que se mirase su causa como meramente nacional española sin proyectos ni miras sobre el restablecimiento en Francia de la rama primogénita, que formé juicio de que las proposiciones hechas han venido de Berlín; pero habían ido a Berlín de París» 77.

A continuación indicaba que tanto Ancillon como Brassier de Saint Simon eran miembros de familias francesas huidas durante la revolución, por lo que se podían mostrar muy sensibles a la sugerencia del Gobierno de su antiguo país.

El segundo punto coincidía plenamente con el propuesto por Prusia en Turín, aunque se formulaba de forma más sencilla, y añadiendo la matización de que no se oponía al principio monárquico. La cuestión de la Inquisición coincidía con la propuesta sarda, y resultaba lógica viniendo de Prusia, en cuyos territorios había una importante población protestante. Labrador señala que tanto Ancillon como Brassier, y la mujer del ministro francés Duque de la Broglie eran de religión protestante.

El cuarto punto, era una novedad a pesar de que en las distintas conversaciones mantenidas en Turín había salido a colación.

Antes de adentrarse en territorio carlista, Maurice Haber mantuvo una conversación con el Sub-Prefecto de Bayona en la que le informó de su misión $^{78}$. Los datos transmitidos por el funcionario francés son los siguientes: los mayores obstáculos para el triunfo de don Carlos son su relación con don Miguel, pretendiente legitimista portugués, y la conexión que los carlistas franceses han pregonado tener con él; las Potencias del Norte exigen a don Carlos que haga una declaración sobre esos temas y negándose a restablecer la Inquisición y prometiendo una amnistía; "Voila ce qu'il est chargé de faire connaître au Prétendant».

77 A.R.A.H. 9/6728. Despacho de Pedro Gómez Labrador, representante carlista en París (21.03.1836 $\left.\mathrm{n}^{\circ} 158\right)$ al Secretario de Estado carlista.

78 A.M.R.E. C.P. Espagne 774, fol. 25. Despacho confidencial del Sub-Prefecto de Bayona (24.01.1836) al Ministro del Interior. 
El 26 de enero de 1836 Cerruti daba cuenta de la llegada del barón Maurice de Haber al Cuartel Real carlista y del contenido de su misión, que consideraba había sido gestada en París:

«Un des commis de la maison qui a conçu l' idée du cadeau a envoyé ici un de ses amis avec un schall tout à fait copié sur le modèle de celui, qu'on a apporté. Il n'y a d'autre différence entre l'un et l'autre si non que le dernier arrivé a quelques franges de plus, et que le premier est plus simple et par conséquent moins choquant. Le schall dont il s'agit a été acheté à Paris»79.

El Conde Solaro se mostró muy sorprendido por esta nueva iniciativa prusiana: «Etonné d'apprendre que la Cour de Prusse eut envoyé une personne auprès de D. Carlos, au moment même où, à sa demande, nous venions d'y envoyer quelqu'un nous-mêmes, j'en témoignai ma surprise à Mr. Le Comte de Truchsess» ${ }^{80}$. Tras estas gestiones el Gobierno Prusiano desautorizó la misión del Barón de Haber, según el propio Solaro, extremo que choca con el hecho de que se contestase a su escrito y más aún con que se remitiese a la Embajada prusiana en París.

El financiero Haber fue recibido de forma casi inmediata por el Pretendiente a quien enseñó la carta de Brassier de Saint Simon. Don Carlos solicitó la entrega del texto a fin de poder estudiarlo detenidamente.

El 30 de enero escribía al Secretario de Estado carlista, Carlos Cruz Mayor, una carta a la que acompañaba copia de la que le había dirigido Brassier ${ }^{81}$. La carta no guardaba las formalidades diplomáticas usuales, puesto que estaba escrita en un lenguaje muy directo, hasta el punto que podría ser calificado de cortante.

En el texto afirmaba venir en representación de los Embajadores de Rusia, Austria y Prusia, aseveración que parece plausible aunque no consta en la documentación austriaca. Y aprovechaba esta afirmación para plantear el texto en términos casi conminatorios:

«...ils [Embajadores] ont même ajoutés que les vues y prononcées sont entièrement d'accord avec celles de leurs Cabinets; en conséquence si le Roi daigne s'y conformer Il pourra compter sur un appui tant désiré en Europe et son effet moral ne manquera pas à se faire sentir bientôt» ${ }^{82}$.

A continuación transfería la responsabilidad del éxito de la misión a Cruz Mayor («c'est a Vous Monseigneur de faire le reste»), y se disculpaba por la irregu-

79 A.S.T. M.D.S.T. Cartella 3. Despacho de Paolo Cerruti (26.01.1836) al Conde Solaro.

80 A.S.T. LL.MM. Francia 304. Despacho (Gabinete particular) del Conde Solaro (17.05.1836) al Conde de Sales, Embajador sardo en París.

${ }^{81}$ A.R.A.H. 9/6727. Carta de Maurice Haber (30.01.1836) al Secretario de Estado carlista.

82 A.R.A.H. 9/6727. Carta de Maurice Haber (30.01.1836) al Secretario de Estado carlista. 
laridad de su propuesta, situación motivada por la coyuntura política que estaban atravesando (Cuádruple Alianza, necesidad de actuar con precaución, etc.).

Finalizaba la misiva señalando que la buena acogida que habían tenido sus palabras le hacían esperar una respuesta positiva, que solicitaba fuere remitida a la mayor brevedad.

Maurice Haber se mantuvo en territorio carlista hasta principios de marzo, fecha en que regresó a Francia ${ }^{83}$. Maroto señala que durante su estancia en el Cuartel Real el Barón le visitó en diversas ocasiones, lo que dio lugar a que la camarilla de don Carlos le «hiciese marchar para Tolosa y a Haber fuera de las provincias».

A finales de marzo de 1836, Pedro Gómez Labrador, representante carlista en París, transmitió a sus superiores el contenido de una conversación mantenida con el embajador prusiano Werther. La reunión se realizó a iniciativa de Labrador, quien deseaba obtener datos sobre el origen de las «manifestaciones hechas en ese Cuartel Real por el Barón Mauricio Haber», y en el curso de la misma le mostró su extrañeza por la forma en que habían sido hechas las proposiciones ${ }^{84}$.

Werther trató de restar importancia al hecho señalando que se trataba de «meros consejos de amistad», ya que la remisión de proposiciones exigía unas formalidades que en este caso no se habían cumplido.

Tras su regreso volvió a entrevistarse con el Sub-Prefecto a quien informó sobre las interioridades de la Corte carlista ${ }^{85}$. En opinión del Cónsul español en Bayona «el tal personaje da una triste idea del estado de finanzas en que se halla el Pretendiente...».

Un mes más tarde saltaba la alarma en las Cortes conservadoras. Metternich transmitía a su Embajador en París la nota enviada por el Conde Waldbourg-Truchsess, embajador prusiano en Turín, al Rey de Prusia:

«Mes craintes relativement aux conséquences d'avoir confié à Mr. de Haber une commission semblable à celle dont fut chargé Mr. Ceruti, n'étaient malheureusement que trop fondées. Une lettre de Bayonne du 3 de ce mois informe le Comte Solar de la Marguerite, que ce juif, digne émule de Deutz, et furieux de se voir échapper l'emprunt négocié à Londres sans sa médiation, a communiqué toute sa correspondance avec V.E. à Mr. Poultier, Sous-Préfet à Bayonne, et lui a dénoncé Mr. Ceruti comme agent du Roi Charles Albert auprès de Don Carlos,

83 A.R.A.H. 9/6794. En la información sobre pases concedidos por la Secretaría de Estado hay dos referidos a Haber: 10 de febrero permiso para seguir al Cuartel Real; 5 de marzo permiso para dirigirse a Francia. A.H.N. Estado 6984. Despacho del Cónsul español en Bayona (10.03.1836 n 81) al Embajador en París, señalando que la noche anterior había llegado a Bayona. Pirala Criado, Antonio. Vindicación p. 60.

${ }_{84}$ A.R.A.H. 9/6728. Despacho de Pedro Gómez Labrador, representante carlista en París (21.03.1836 $\left.\mathrm{n}^{\circ} 158\right)$ al Secretario de Estado carlista.

85 A.H.N. Estado 6984. Despachos del Cónsul español en Bayona (10.03.1836 $\mathrm{n}^{\circ}$ 81; 12.03.1836 n $\mathrm{n}^{\circ}$ ) al Embajador en París. 
pour se venger de l'affront qui lui a été fait au quartier général, à ce qu'il dit. Il compromit toutes les personnes avec lesquelles il s'est trouvé en relation. Mr. Cazes, agent secret de Louis Philippe, se trouve aussi à Bayonne de concert avec $\mathrm{Mr}$. Haber, et celui-ci, ayant entièrement jeté le masque, est considéré comme un des principaux collaborateur de police» 86 .

En opinión de Metternich la actuación de Maurice Haber estaba motivada por haber sido excluido de la negociación del empréstito carlista concluido en Londres. Entre los personajes comprometidos se encontraba Joaquín Abarca ${ }^{87}$.

Desde diversos medios llegaban las noticias sobre las informaciones pasadas al Ministerio del Interior francés, en las que además se criticaba el haber escogido para una misión tan delicada a una persona de tan escaso prestigio ${ }^{88}$.

No resulta extraño que Solaro conocer de todas estas noticias escribiese a su Embajador en París:

«Je ne m’étonne pas que Mr. Haber ait tout révélé à la Police à Paris, en retournant du Quartier général de don Carlos il avait déjà fait son rapport au SousPréfet de Bayonne, et dès lors j'avais pensé que la mission de Prusse avait fort mal placé sa confiance en lui pour une affaire aussi délicate»89.

Meses más tarde se le mencionaba nuevamente como el instigador de una campaña de desprestigio contra los carlistas ${ }^{90}$.

${ }_{86}$ H.H.St.A. G.A. Paris 44. Anexo al despacho secreto del Príncipe de Metternich (30.04.1836 $\mathrm{n}^{\circ}$ 6) al Conde Appony. La nota de Waldbourg-Truchsess tenía fecha de 12 abril de 1836.

87 B.N.P. Mss. Espagne 585, fol. 119. Despacho de Manuel Aznárez (25.04.1836) a Joaquín Abarca: «... yo sé quién ha sido el que le ha vendido a V.; lo sé de cierto por boca de un alto personaje; el que ha vendido a V. Ha sido Haber: no lo dude V. Ni un instante; es cierto, certísimo...». Un día más tarde (fol. 120) en una carta al don Carlos señala que Sebastiani, Embajador francés en Londres, le había comunicado que Haber era el delator.

88 A.S.M.A.E. S.S. Sardegna R.P.D. 12. Despacho del Barón de Blonay, representante sardo en París (13.05.1459) al M.A.E: «Sur des renseignements que Mr. D’Appony a reçu et qu'il croit exacts il paraîtrait que ce Mr. de Haber, qui ainsi que V.E. le sait, a fait dernièrement le voyage de Navarre dans les intérêts, disait-il, de D. Carlos, auquel il s'était présenté, et qui est actuellement de retour à Paris, vient de se rendre a la Police française; ce qui prouverait combien il faut se méfier de cette espèce d'aventuriers politiques».

89 A.S.M.A.E. S.S. Sardegna R.P.D. 12. Post scriptum del despacho de Solaro (18.05.1836 n ${ }^{\circ}$ 3204) al Embajador sardo en París.

90 A.R.A.H. 9/6776. Despacho de Aznárez, representante carlista en Londres (9.03.1837 n ${ }^{\circ}$ 564) a la Secretaría de Estado carlista, en el que remite un recorte del Courier del día 8 conteniendo una carta de un legitimista con criticas a los carlistas por el fusilamiento de los legionarios ingleses en Hernani. Añade este comentario «Casi puedo asegurar a V.S. que el autor de este artículo es el Barón Haber....». 


\section{LA RESPUESTA CARLISTA.}

La documentación existente permite señalar que mientras que la propuesta realizada a través de Cerdeña no provocó excesivas reacciones en los medios carlistas, podemos encontrar duras críticas a la actuación de Maurice Haber. Una de las diferencias más notables entre ambas iniciativas es que mientras que Haber denunció a los carlistas de forma casi inmediata, Cerruti permaneció, durante algún tiempo, en el Cuartel Real actuando como representante oficioso de Cerdeña.

Al parecer no todos los seguidores de don Carlos eran partidarios de un rechazo cerrado de las propuestas. Según el Sub-Prefecto de Bayona los carlistas moderados estaban de acuerdo con el documento entregado por Haber ${ }^{91}$.

Para responder a ambas iniciativas Carlos Cruz Mayor elaboró un largo documento en el que se respondía a todas las propuestas de forma conjunta, y que sirvió de base a los textos que se enviaron posteriormente. Sin duda alguna tras la aprobación del Monarca se elaboraron dos documentos diferentes para diferenciar claramente tanto el contenido, cada escrito había hecho propuestas diferentes, como el tono de la respuesta.

Existen en total cuatro documentos diferentes relacionados con las propuestas prusianas, que es preciso diferenciar claramente. La identificación de cada uno de ellos no presenta demasiadas complicaciones, porque su contenido responde claramente a las diferentes insinuaciones o consejos realizados:

a) Documento de respuesta global elaborado por Carlos Cruz Mayor, y que sirvió de base a los dos siguientes ${ }^{92}$.

b) Documento enviado a la Corte sarda ${ }^{93}$. Dicha respuesta fue comunicada de forma oficial al Gobierno sardo mediante una carta de Carlos Cruz Mayor, fechada el 1 de marzo de 1836.

c) Documento enviado al Marqués de Labrador para que informase a la Embajada prusiana en París, que debió ser remitido en la primera mitad del mes de marzo ${ }^{94}$. El autor es Carlos Cruz Mayor, como se puede dedu-

${ }_{91}$ A.M.R.E. C.P. Espagne 774, fol. 82. Despacho del Sub-Prefecto de Bayona (16.03.1836) al Ministro del Interior francés

92 A.R.A.H. 9/6726. Se trata de un texto extenso, redactado en castellano, que alcanza las 40 páginas y que ha sido publicado en Bullón de Mendoza, Alfonso. «Informe de Cruz Mayor».- Aportes.(noviembre 1991-febrero 1992) no 18 ; p. 44-60. Resulta preferible recurrir al original ya que en el texto publicado por Bullón de Mendoza existen varios defectos: errores de trascripción (Brafsier por Brassier, etc.), errores en la introducción (sitúa las iniciativas a finales de 1834 en lugar de 1835), no se anotan los errores del documento (Pedro Cerruti por Paolo Cerruti), no hay anotación del texto, no se explica el contexto del documento, se desconoce la bibliografía relacionada con dicha cuestión, etc.

93 A.R.A.H. 9/6726 (borrador). A.S.T. C.P.D. 18 (original). Se trata de un texto redactado en francés, que alcanza las 14 páginas en el borrador y 10 en el original remitido a Turín.

94 A.R.A.H. 9/6740. Se trata de un menos extenso que el anterior, redactado en castellano, que alcanza las 10 páginas y que ha sido publicado en Bullón de Mendoza, Alfonso. «Informe de Juan 
cir fácilmente de la rúbrica existente al final del texto, a pesar de que Bullón de Mendoza lo considera obra de Juan Bautista Erro sin justificar esta atribución.

d) Resumen del texto realizado por Pedro Gómez Labrador para ser entregado al Embajador prusiano95. Según sus palabras en la elaboración del resumen había seguido las siguientes pautas: «... he conservado lo más esencial de la respuesta y por medio de frases generales satisfecho a lo que deseaba la corte de Prusia, sin comprometer en nada la libre disposición, que debe tener el Rey N.S. en el ejercicio de su clemencia y demás prerrogativas, cuando haya triunfado de la usurpación y de la revolución que se apoya sobre ella».

\subsection{La memoria redactada por Carlos Cruz Mayor}

La memoria escrita por Carlos Cruz Mayor tiene un gran valor porque se trata de un texto tremendamente sincero, en el que se adopta un lenguaje muy directo ya que el número de lectores es reducidísimo y todos ellos integrantes del círculo de confianza de don Carlos. Existe una gran diferencia entre ella y los productos finales que fueron enviados a París y Turín, en los que se eliminan expresiones duras que incluso pueden ser consideradas ofensivas.

Se inicia con una información sobre el origen del documento en la que se distinguen claramente las dos iniciativas: Cerruti («en comisión especial de su Augusto Soberano») y Haber («con encargo, según parece de la Embajada de Prusia en París»).

Tras resumir las peticiones de los dos documentos en una lista única, Cruz Mayor pasaba a responder a cada una de las cuestiones propuestas, hacía una introducción general, en la que valoraba los hechos y plateababa los principios sobre los que debería asentarse la respuesta:

«Nunca he opinado, Señor, desde que tuve la honra de seguir a V.M. a estas fieles provincias, que fuese político y conveniente el que V.M. estampase en públicos manifiestos sus miras o proyectos respecto al gobierno interior de Sus Reinos, y mucho menos en el periodo en que actualmente nos hallamos y con los antecedentes que existe» 96 .

Bautista Erro».- Aportes.- (marzo-junio 1992) nº 19; p. 82-89. Bullón se equivoca en la autoría, y sobre ella crea toda una teoría de variación ideológica entre Cruz Mayor y Erro, cuando se trata de algo mucho más simple: un primer documento destinado al Pretendiente, en el que el lenguaje puede ser más directo y se pueden hacer determinadas afirmaciones, y otro con un destino más público en que es necesario pulir términos y contenidos. A.R.A.H. 9/6740. Memoria enviada a Pedro Gómez Labrador p. 6. se dice que el documento remitido a Turín fue despachado «hace pocos días».

${ }_{95}$ A.R.A.H. 9/6728. Anexo al despacho de Pedro Gómez Labrador, representante carlista en París (4.04.1836 $\mathrm{n}^{\circ}$ 168) al Secretario de Estado carlista. A.S.T. LL.MM. Francia 262. Anexo al despacho del Embajador sardo en París (3.05.1836 n ${ }^{\circ}$ 1452) al Conde Solaro.

96 A.R.A.H. 9/6726. Informe de Carlos Cruz Mayor p. 8. 
La justificación de este principio de independencia absoluta respecto a los monarcas conservadores estaba fundamentada en una serie de hechos:

En primer lugar se aducía que la presencia del Pretendiente en territorio español había sido fruto de su valiente decisión, sin que nadie se lo hubiese aconsejado, y viéndose obligado a correr serios peligros al atravesar un territorio que le resultaba hostil.

Un segundo razonamiento se centraba en la inutilidad de la publicación de semejante texto, ya que las Cortes Conservadoras habían adoptado una actitud de distanciamiento, que no tenía visos de modificarse.

En apoyo de esta afirmación citaba el escaso apoyo recibido hasta el momento: «... a nadie debe V.M. esta satisfacción, porque ninguna potencia se ha declarado abiertamente protectora de la causa de V.M., ni ha prestado garantías sólidas del interés que ésta le inspiraba, ni cooperado eficazmente a los triunfos que V.M. ha obtenido contra los rebeldes ${ }^{97}$. Y salía al paso de las posibles objeciones argumentadas sobre la ayuda recibida, cuya importancia minimiza, porque fue conseguida tras laboriosas gestiones, y ha sido escasa y muy dividida, lo que ha impedido que se convirtiese en un factor decisivo para la victoria. En este punto mencionaba asimismo que las Cortes conservadoras habían sido incapaces de obligar a Francia e Inglaterra a mantener la neutralidad ante la guerra, a fin de que se mantuviese como una cuestión meramente española. Cruz Mayor señalaba a continuación cuáles eran las únicas referencias que debían guiar su conducta:

«Fuerte V.M. del derecho que le asiste, fuerte del amor y de la decisión de sus valientes tropas, y descansando en la protección de la Divina Providencia que tan visiblemente se ha declarado por V.M., éstos son los verdaderos apoyos con que V.M. debe contar sin recelo para llevar a cabo la acometida empresa, si los que pueden anticipar su feliz éxito pretenden hacerlo coartando el libre ejercicio de sus Reales facultades y prerrogativas que no han de amoldarse sino a las exigencias de los intereses de sus pueblos, de su Corona, y del esplendor y auge de la verdadera Religión» 98 .

A ello añadía que, tal como le había señalado en diversas ocasiones, aunque se cumpliesen todos los consejos transmitidos, no variaría su forma de actuar y no procederían a su reconocimiento en tanto no llegase a dominar la mayor parte del territorio. Y en ese momento lo harán por su propio interés y no por ayudar a la causa realista en España, decisión que estaría motivada para adelantarse al pragmatismo de Francia e Inglaterra.

Con ello no defendía una política de aislamiento que acabaría enfrentándole a otros monarcas, cuya ayuda podría ser muy beneficiosa para acabar cuanto antes la guerra, sino que se trataba de no hipotecar el «porvenir de la Nación que Dios le ha confiado a su custodia»99.

\footnotetext{
97 A.R.A.H. 9/6726. Informe de Carlos Cruz Mayor p. 9.

98 A.R.A.H. 9/6726. Informe de Carlos Cruz Mayor p. 10-11.

99 A.R.A.H. 9/6726. Informe de Carlos Cruz Mayor p. 12.
} 
En resumen el elemento que sustentaba todo el texto de Cruz Mayor era la necesidad de mantener inalterable la herencia que había recibido, la monarquía absoluta emanada del poder divino.

La introducción finalizaba desmintiendo que las propuestas fuesen fruto de un acuerdo de las Cortes conservadoras en su reunión de Toeplitz, pues en ellas se había aprobado el principio de no injerencia en las cuestiones internas de otros países. En su opinión se trataba de una injerencia del Ministro de Exteriores prusiano, Ancillon. A pesar de ello, por deferencia a las ayudas recibidas de dicho país y a la intermediación de la Corte sarda, resultaba necesario responder.

A continuación entraba de lleno en el análisis de cada uno de los puntos sugeridos en ambas notas.

Consideraba innecesaria y perjudicial una declaración en favor de los fueros ya que se había realizado el juramento de su preservación bajo el árbol de Guernica, acto que había sido acompañado de la publicación de un decreto comprometiéndose a su conservación. Una reiteración de sus palabras podría hacer generar suspicacias sobre la validez de sus promesas. Sin embargo se mostraba contrario al restablecimiento de las antiguas instituciones que habían desaparecido, ya que su defensa no había sido un elemento importante en la decisión de defender la causa carlista.

Consideraba que la división en pequeños reinos había resultado nefasta, porque había provocado continuas guerras, y que su restauración implicaría retroceder a una situación ya superada. En la argumentación había una notable influencia del principio centralizador que había inspirado la política del reinado de Fernando VII. El mantenimiento de la estructura centralizada y unificada evitaría el debilitamiento de España, e impediría las ambiciones británicas y francesas por poseer algunos puntos importantes del territorio.

Cruz Mayor daba por zanjada la cuestión de las legislaciones provinciales porque sería «destruir el equilibrio de las naciones que tantos esfuerzos ha costado establecer», y defendía el principio del inmovilismo como medio de estabilidad.

A continuación entraba a analizar la solicitud de publicación de un manifiesto en que don Carlos justificase los derechos que le asistían para aspirar al trono español y el llamamiento a las Potencias, texto que contendría una declaración con seguridades sobre su comportamiento moderado. El político carlista consideraba este punto «innecesario, si no extraño e incomprensible» ${ }^{100}$. Y en este punto volvía a introducir una declaración sobre los principios que se deberían aplicar:

«... no está en los intereses de los llamados liberales el permitir que a él ascienda V.M. porque temen su carácter recto y justiciero y que con mano fuerte reprimirá la licencia, sujetará las ambiciones desmedidas, y pondrá un freno saludable a las pasiones políticas, haciendo respetar las leyes, la Religión y la autoridad»101.

100 A.R.A.H. 9/6726. Informe de Carlos Cruz Mayor p. 19.

${ }_{101}$ A.R.A.H. 9/6726. Informe de Carlos Cruz Mayor p. 20. 
Les resultaba sorprendente que las Potencias signatarias del tratado de Utrecht solicitasen una justificación de los derechos derivados del mismo, entre los cuales se encontraban las modificaciones introducidas en el sistema sucesorio por Felipe V. El documento que se solicitaba había sido ya realizado cuando tras su entrada en territorio español don Carlos se dirigió a los Soberanos que no habían reconocido a Isabel II

«participándoles su venturoso arribo, su firme determinación de recuperar su Trono usurpado o de sucumbir con gloria y con honor, sin ahorrar, antes de desenvainar el acero, los medios que le dictaba su paternal corazón para atraer y desarmar a los que aún se dignaba no considerar sino como hijos extraviados, y que así lo cumplió V.M. ofreciendo reiteradamente a éstos olvido y perdón si se sometían»102.

El tercer punto objeto de litigio era la posición frente a Francia e Inglaterra. Este apartado se iniciaba con un memorial de agravios sobre la conducta de dichos Gobiernos tanto respecto a la causa carlista en general, como respecto a los partidarios de don Carlos. A pesar de la dureza con que se introducía el tema, Carlos Cruz Mayor adoptaba una posición muy posibilista y consideraba

«un medio conveniente y político de abreviar la lucha, el calmar en cierto modo las prevenciones y los recelos de la Inglaterra y de la Francia, respecto de V.M., dándoles a entender indirecta y mañosamente que V.M. se halla dispuesto a correr un velo sobre los agravios recibidos, a reconciliarse con ellas, y una vez en su Trono a respetar los derechos bien o mal adquiridos de los Reinantes sus vecinos, a seguir la política general de las demás potencias y a no ocuparse sino del buen gobierno, de la tranquilidad, de la dicha y prosperidad de sus pueblos»103.

En la redacción de este punto resulta clara la experiencia de trabajo de su autor en la Secretaría de Estado, ya que opta por una solución fuertemente realista, obviando encasillamientos ideológicos cerrados.

El cuarto punto de las propuestas conjuntas hacía referencia a la conveniencia de atraer a personalidades del «partido de la Reina viuda, dejándolas esperar que obtendrán gracias».

La respuesta se inicia con una descripción de la importancia que tienen las personas que rodean al Soberano, que pueden influir de forma notable en las decisiones que él adopte. Deben ser por lo tanto hombres de «toda confianza, de toda rectitud, de una fidelidad a toda prueba», condiciones todas ellas que no pueden reunir quienes por su propio interés han sido contrarios a don Carlos.

Su inutilidad sería total porque ni existen elementos para depositar en ellos la confianza, ni cabe presumir que puedan actuar sobre María Cristina para que

${ }_{102}$ A.R.A.H. 9/6726. Informe de Carlos Cruz Mayor p. 22.

${ }_{103}$ A.R.A.H. 9/6726. Informe de Carlos Cruz Mayor p. 25. 
abandonen la contienda, ni que no vayan a exigir por su cambio de bando condiciones inadmisibles. Su postura estaba además influenciada por su oposición a cualquier tipo de transacción que implicase concesiones ideológicas.

La quinta respuesta hacía referencia a la necesidad de no crear un frente legitimista integrado por las reivindicaciones españolas, francesas y portuguesas. En esta respuesta volvía a primar en Cruz Mayor el hombre de estado, con conocimientos de política internacional, sobre el ferviente absolutista. En diversas ocasiones había informado contra las propuestas que tendían a tal finalidad, especialmente las enviadas por el Conde de Canellas, agente de don Miguel de Portugal.

La alianza con éste último provocaría una dura reacción por parte de Inglaterra, cuyos intereses comerciales en dicho territorio eran muy conocidos. No cabe esperar que ningún gobierno británico apoyase la restauración portuguesa, porque «la opinión general, en la Gran Bretaña, está en contra de señor don Miguel» ${ }^{104}$. Todo ello no sería obstáculo para que le ayudase, una vez ocupada la Corona española y siempre sin perjudicar «los intereses preferentes de sus amados pueblos».

La cuestión francesa resultaba más sencilla, porque Luis Felipe estaba atemorizado con la radicalización del Gobierno de María Cristina, que le hacía temer llegase a la proclamación de la república. Por ello proponía como

«indispensable disipar las inquietudes de los dos aliados de la usurpación, haciéndoles entender, aunque sea por medios indirectos, que V.M. de lo que trata es únicamente de reconquistar sus Estados, y que alcanzado este objeto, sólo aspirará a labrar la felicidad de sus vasallos y a vivir en paz y buena armonía con sus vecinos» 105 .

En el apartado referente al posible restablecimiento de la Inquisición volvía a plantearse en Cruz Mayor el dilema entre su exagerado conservadurismo religioso y su experiencia internacional. Reconocía obviamente la mala fama de dicha Institución, motivada por su ignorancia sobre su funcionamiento real, especialmente en ciertos países europeos en los que se practicaban otras religiones, pero descalificaba a Prusia y otros países porque no "pueden fallar con imparcialidad en semejante negocio». Su propuesta consistía en no comprometerse en una negativa

«...si no podría V.M una vez en plena posesión de su Trono, consultar hombres religiosos, doctos, de sano juicio y rectas intenciones y bien instruidos de las necesidades de la época, del estado de la España y de los verdaderos intereses de la Religión, del Trono y de los pueblos, a fin de que con madurez determinen si en caso de ser necesario reponer la Inquisición no podría variarse el nombre, la

${ }_{104}$ A.R.A.H. 9/6726. Informe de Carlos Cruz Mayor p. 31.

${ }_{105}$ A.R.A.H. 9/6726. Informe de Carlos Cruz Mayor p. 32. 
forma y las atribuciones que tan exaltada impresión han dejado en los ánimos, y sustituir a dicho Tribunal otra institución que por diferentes medios produzca los mismos efectos»106.

A pesar de su interés por conservarla, proponía comunicar a las Cortes extranjeras que en ninguna ocasión había dicho o hecho nada que permitiese pensar que tenía intención de reponer la Inquisición, redactando una fórmula que no le condicionase su forma de actuar en el futuro.

El último apartado, y no el menos importante estaba dedicado a comentar la propuesta de publicación de una amnistía. Resulta evidente que su mención desataba pasiones muy encontradas en el seno del carlismo, como se evidencia en la extensión y énfasis con que se aborda.

Cruz Mayor hace una relación de todas las imputaciones contra los liberales (asesinatos, quemas de iglesias, nivelación social, etc.), todas ellas graves delitos. Pero al mismo tiempo señalaba que la medida resultaba completamente inútil, ya que debería estar destinada a «los corazones extraviados pero arrepentidos», circunstancia que no se daba en este caso ya que

«los revolucionarios del día son los mismos que los que figuraron en los desórdenes de los tres años, del 20 al 23, los mismos que cubrieron entonces la España de luto, que diez años de reflexión y de desengaño no han podido convertir, y muchos de los cuales indultados en el transcurso de dicha época y repuestos en destinos por el Augusto hermano de V.M. el Sr. D. Fernando $7^{\circ}$, han correspondido a sus bondades con la más negra ingratitud, y han abusado de su confianza para minar el edificio de nuestras leyes fundamentales, derribar la Monarquía de Felipe V y sumir su desventurada patria en el más horroroso caos»107.

La amnistía sería un insulto para los fieles y sobre todo para quienes hayan sufrido durante la guerra, pero ello no le llevaba a solicitar un castigo generalizado, que debería reducirse a los cabecillas, a los que han prestado una colaboración importante aunque fuese en puestos secundarios y a los que han sido los ejecutores de los desmanes, es decir, «todos aquellos que han tenido una parte activa sea directa o indirecta en las rapiñas, incendios, sacrilegios, asesinatos y crímenes de toda clase».

En ningún caso se debe permitir la amnistía de estos delitos, de la misma forma que lo hacen los Soberanos que han dirigido la solicitud.

Los párrafos finales de la memoria son un doble recordatorio para el Pretendiente. Por una parte le alertaba contra los que ocultamente trabajan para el enemigo, ya que está poniendo en peligro a los files servidores; en segundo lugar hacía un firme declaración de fidelidad y salía al paso de las calumnias y las intrigas de sus adversarios.

106 A.R.A.H. 9/6726. Informe de Carlos Cruz Mayor p. 34.

${ }_{107}$ A.R.A.H. 9/6726. Informe de Carlos Cruz Mayor p. 36. 


\subsection{La respuesta a la Corte de Turín}

Tomando como base la memoria de Cruz Mayor, se elaboró un texto destinado a ser remitido a Solaro, y posiblemente el propio Cerruti actuó como correo si tenemos en cuenta las fechas de la carta de remisión (1 de marzo) y la fecha de regreso del representante sardo a su país (mediados de marzo). El texto conocido está redactado en francés.

Se iniciaba con una declaración de amistad y de reconocimiento a las Cortes de Cerdeña y Prusia por el interés que demostraban con su propuesta y las claras muestras de apoyo a don Carlos. Pero ello no impedía a don Carlos señalar que en la valoración de los consejos se tuviese que atener a «la raison d'État et d'autres motifs qui, pour n'être pas à la portée de tout le monde, ne sont pas moins dignes des plus sérieuses méditations» ${ }^{108}$.

Y descalificaba globalmente las sugerencias señalando que nadie salvo los naturales podían emitir un juicio sobre un sistema de gobierno o sobre las posibles reformas. Hacía la salvedad de incluir en este grupo a «ceux qui y ont fait un très-long séjour et qui s'y sont dédiées à une étude approfondie des hommes et des choses» ${ }^{109}$. De esta forma se permitía que personas como Solaro no se sintiesen molestas por dichas referencias. Por ello incluso las personas mejor intencionadas podían ser inducidas a error. Resultaba por lo tanto lógica la conclusión siguiente:

«Partant de ce principe et en admettant l'application à l'Espagne, on ne s'étonnera plus que le Roi Charles $\mathrm{V}$ ne se soit pas décidé à faire usage de quelques uns des moyens moraux que le Cabinet Prussien suggère; d'autant moins si en lui rendant la justice qu'il mérite, on a une entière confiance en sa droiture, en ses vertus et en son sincère désir de faire le bonheur de ses sujets»110.

El primer punto abordado es el referente a la necesidad de publicar un documento comprometiéndose a mantener las antiguas instituciones provinciales.

En la respuesta se mencionaba expresamente la palabra dada por el Pretendiente de mantener los fueros de Navarra y Provincias Vascongadas, pero evitaba pronunciarse sobre una rehabilitación generalizada de las leyes de los antiguos territorios que integraban la Corona. Consideraba innecesario el documento porque los habitantes de las provincias que estaban bajo su dominio confiaban en la palabra que les había dado. La devoción y confianza de sus súbditos era absoluta, y lo único que se necesita para extender la sublevación era apoyo financiero y de material. Y finalizaba la argumentación con estas palabras:

\footnotetext{
108 A.R.A.H. 9/6726 (borrador) p. 1. A.S.T. C.P.D. 18 (original) p. 1.

109 A.R.A.H. 9/6726 (borrador) p. 1. A.S.T. C.P.D. 18 (original) p. 1.

110 A.R.A.H. 9/6726 (borrador) p. 2. A.S.T. C.P.D. 18 (original) p. 2.
} 
"Ceux qui hésitent à se déclarer pour Lui, ce sont ceux seulement qui se sont trop compromis, qui ont trop avancé pour oser reculer. Tout le reste est plein de confiance en lui ; on l'attend partout les bras ouverts, comme le sauveur de la patrie, comme l'ange tutélaire de paix, d'union et de félicité. Toutes les correspondances de l'intérieur de l'Espagne sont unanimes sur ce point; et quand le moment favorable sera venus, les gens les plus incrédule se convaincront de cette assertion et rendront hommage à la vérité»111.

Esta afirmación, que los políticos carlistas repetían asiduamente, sobre todo ante los Gobiernos con los que mantenían relaciones, se volvió contra ellos tras el fracaso de la expedición de Gómez y la Expedición Real. Situación de la que salieron bastante malparados ${ }^{112}$.

Sobre el sistema político que pensaba adoptar en sus estados se limitaba a señalar que era el mismo de sus predecesores, tratando de corregir aquellos abusos que pudieran haberse introducido. Se hacía una declaración de contenido fuertemente contrarrevolucionario, mucho más rígido que el de los países que habían vencido a Napoleón, al afirmar que tenía obligación de entregar a sus sucesores la Corona en las mismas condiciones en que la había recibido. Y muy en la tradición de Burke señalaba que no era posible exportar modelos políticos, pues éstos debían adaptarse a las circunstancias locales, al carácter de los peninsulares y con leyes modeladas sabiamente a través de los tiempos ${ }^{113}$.

Tras este punto y muy conectado con el mismo se abordaba la propuesta de elaboración de un manifiesto explicando sus derechos al Trono y dando seguridad de que actuaría con moderación tras la victoria. En este apartado la identidad de argumentos con el documento que servía de base era casi total.

Se aducía la opinión universal, incluso entre sus enemigos, de que le asistían todos los derechos para aspirar al Trono, y que la oposición de aquellos se basada en que tenían miedo de su carácter justo y firme, opuesto a cualquier veleidad revolucionaria. Les recordaba que sus derechos estaban basados en el tratado de Utrecht, del cual eran signatarios y garantes los mismos que ahora le pedían explicaciones y mencionaba las cartas que les había remitido tras su regreso a España, en las que explicaba su firme determinación de recuperar el Trono, y que aún permanecían sin respuesta. E introducía como novedad una mención altamente significativa:

111 A.R.A.H. 9/6726 (borrador) p. 6. A.S.T. C.P.D. 18 (original) p. 4-5.

112 José Ramón Urquijo Goitia. «El Carlismo y Rusia».- En : Hispania.- XLVIII (1988) nº 169, p. 615 y ss. José Ramón Urquijo Goitia. «Los Estados Italianos y España durante la Primera Guerra Carlista (1833-1840)».- En : Hispania.- LII (1992) no 182, 964 y ss. José Ramón Urquijo Goitia. Relaciones entre España y Nápoles durante la Primera Guerra Carlista.- Madrid : Actas, 1998; p. 291 y ss.

113 Sobre la ideología del carlismo véase la obra de Alejandra Wilhelmsen. La formacióndel pensamiento político del carlismo (1810-1875).- Madrid : Actas, 1995; p. 183 y ss. Las tesis de Burke en Elmund Burke. «Reflexiones sobre la Revolución Francesa 1790».- En : Textos políticos.- México : Fondo de Cultura Económica, 1984 (primera reimpresión). Dicha tesis está presente en toda la obra. 
«D’un autre côté il n'est à présumer que ces monarques considèrent les actes arbitraires de la faction, qui gouvernait au nom de Ferdinand 7 , un an avant sa mort et depuis les événements de la Granja, comme des actes capables d'invalider une loi aussi importante que celle de succession au trône et ceci au détriment de l'héritier présomptif»114.

Esta innovación del texto estaba destinada a recordarles sus presiones en contra de la modificación del orden sucesorio, en vida aún de su hermano, mientras que ahora le exigían que explicase sus derechos, que al parecer los tenían muy claros tres años antes.

Las referencias a las relaciones con Francia e Inglaterra se iniciaba con el rechazo de que por parte carlista hubiese intención de ofender a dichos Gobiernos. A diferencia del texto base se mencionaba expresamente la información que había sido realizada por Solaro referente a los escritos publicados en la $\mathrm{Ga}$ ceta oficial, y en lugar de la larga enumeración de agravios se hacía una mención genérica a los mismos, y una específica de ser los principales responsables del alargamiento del conflicto.

Finalizaba el apartado con una declaración expresa de sus deseos de mantener buenas relaciones con ambos Gobiernos, tal como se les había expresado de forma indirecta en alguna ocasión, y una aceptación de cualquier mediación ante ellas.

El planteamiento relacionado con la conveniencia de atraer notabilidades del partido de la Reina presentaba caracteres más ideológicos. Se repetían los argumentos planteados en el documento base sobre la escasa utilidad de su concurrencia, la nula fiabilidad de su acción, etc. Únicamente se añadía una nueva reflexión basada en que su acercamiento se produciría en el momento que viesen desmoronarse el Gobierno liberal, y en dicha situación no serían necesarias concesiones ni transacciones.

\subsection{El documento enviado a Pedro Gómez Labrador}

Para responder a Haber se elaboró un documento más reducido y con lenguaje mucho más duro, lo que evidencia el desagrado con que recibieron su visita. El texto no se envió al financiero, sino al Marqués de Labrador a través del agente carlista en Bayona, Lagracinière ${ }^{115}$.

La misión de Haber había recibido duras críticas en los medios legitimistas, lo que dejaba pocas esperanzas de que obtuviese una respuesta mínimamente

${ }_{114}$ A.R.A.H. 9/6726 (borrador) p. 8-9. A.S.T. C.P.D. 18 (original) p. 6.

115 A.R.A.H. 9/6728. Despacho de Pedro Gómez Labrador, representante carlista en París (21.03.1836 $\mathrm{n}^{\circ}$ 158) al Secretario de Estado carlista señalando que aún le había entregado el documento. A.M.R.E. C.P. Espagne 774, fol. 82. Despacho del Sub-Prefecto de Bayona (16.03.1836) al Ministro del Interior francés señalando la vía por la que había circulado el documento. 
favorable, sobre todo si uno de los autores de las mismas era el canciller Metternich:

«[Metternich se ha enterado de que] el judío Haber había salido de París para ese Cuartel Real por asuntos de su malhadado empréstito y que llevaba el encargo del Barón de Werther, Ministro de Prusia en París, de dar a S.M. cuatro consejos: el de dirigir alocuciones a sus pueblos que les declarara no se volvería a restablecer el tribunal de la Inquisición y el de ofrecer una extensa amnistía, el otro era insignificante y no se acordaba de él pero todos los cuatro le han incomodado sobre manera porque dice está hace tiempo convencido por la experiencia que en España solo los españoles pueden juzgar lo que les conviene... pero que éste es el furor dominante de Ancillon y que Werther en esta cuestión solo ha tratado de adularle no habiendo podido hacer mejor elección para pedir no se restablezca el Tribunal de la Inquisición que un judío...»116.

La dureza del documento se observa desde la misma introducción. No se entiende la diferencia de contenidos y estilo si tenemos en cuenta que el destinatario final de ambos documentos era el Gobierno de Prusia. Esta variación indica claramente que el autor consideraba que cada texto tenía un destinatario inicial distinto, y sin tener en cuenta este detalle no puede ser interpretado adecuadamente.

La cuestión queda más patente aún si observamos que en la memoria enviada a Pedro Gómez Labrador, tras analizar la cuestión foral se señala:

«Nos extenderíamos mucho más sobre este punto, a no haberlo ya efectuado en otro escrito análogo al presente, que despachamos hace pocos días y que muy en breve obrará en poder del Gabinete prusiano. Y por lo tanto nos abstenemos de dar más latitud a estas observaciones»117.

¿Por qué razón no se enviaba el mismo texto en ambos casos? Sólo cabe deducir que porque el lector inicial de la misiva era diferente y estaba enfocado fundamentalmente a él.

El escrito enviado a Turín, en la mentalidad de Cruz Mayor, no iba dirigido a Prusia sino al Monarca sardo, lo que se evidencia en la suavidad de los términos empleados. A París se enviaba un documento que iba a tener por lectores a los Embajadores de las Cortes conservadoras, contra las que existía un fuerte resentimiento por su escaso apoyo político y material.

Tras repetir el argumento de la imposibilidad de que un extranjero tenga elementos de juicio adecuados para opinar sobre la situación, se extendía en consideraciones sobre la abundancia de calumnias vertidas contra don Carlos.

116 A.R.A.H. 9/6733. Despacho del Conde de Alcudia, representante carlista en Viena (4.01.1836 $\left.\mathrm{n}^{\circ} 335\right)$ a la Secretaría de Estado carlista.

117 A.R.A.H. 9/6740. Memoria enviada a Pedro Gómez Labrador p. 6. 
«Los revolucionarios españoles y extranjeros tienen un interés harto poderoso para desacreditar a S.M., para hacerle odioso. En él ven el emblema de la legitimidad; la salvaguardia, digámoslo así, de las monarquías puras del siglo. Malograda la noble empresa de Carlos V, triunfante en España la revolución, digna secuaz de la usurpación, inmenso era el paso que daban los novadores, porque se allanaba el mayor obstáculo que entorpecía la ejecución de sus designios, los que con tanta perseverancia alimentan en sus tenebrosos clubs, y que tienden, como es notorio, al establecimiento de gobiernos libres o democráticos en el mediodía de la Europa, que formen una liga contra las Monarquías del Norte» ${ }^{118}$.

Este párrafo es una dura crítica a las Cortes conservadoras, que cerraban los ojos ante un peligro que consideraban lejano. A lo largo de la guerra la diplomacia carlista envió este mensaje en numerosas ocasiones, siempre con escaso éxito. Y la falta de audiencia en tales medios le lleva a realizar una dura acusación:

«Y es muy sensible el tener que reconocer que en parte han alcanzado su intento. Esto no sucedería si los Gabinetes extranjeros, si con ellos los legitimistas y los amantes del orden en toda la Europa hubieran estado más sobre sí contra los artificiosos manejos y las intrigas de los revolucionarios que han sorprendido su buena fe. Se tendrá entonces una opinión más correcta y justa de los sucesos de la España y de las intenciones de Carlos V; se repondría en ellas más confianza; y no se insistiría en algunas medidas que se creen útiles e indispensables y pueden resultar perjudicialísimas»119.

La dureza del texto resulta inusitada, porque acusa a los mensajeros de haber sucumbido ante la palabrería de los liberales y haberse convertido en su portavoz, en lugar de situarse en el campo de las causas justas. Esta misma idea se repite en los apartados concretos en que se responde a cada una de las propuestas traídas por Maurice Haber.

Entrando en la respuesta de cada punto concreto se aborda en primer lugar la cuestión relacionada con la unidad de acción entre los realistas de España, Francia y Portugal, respuesta que se inicia con una larga introducción en que se evidencia el malestar carlista y la pésima opinión que tienen sobre sus «interlocutores»:

«Confesaremos que lo que más nos ha sorprendido ha sido la idea que se tiene de que S.M. trata de amalgamar la cuestión de la sucesión al Trono de España con la de otros Reinos. Nada prueba más a las claras, séanos lícito expresarlo, el concepto equivocado que se tiene de su política. Es por cierto hacerle muy poco favor, es agraviar el ánimo esclarecido de este Príncipe el suponerle la intención

118 A.R.A.H. 9/6740. Memoria enviada a Pedro Gómez Labrador p. 2-3.

119 A.R.A.H. 9/6740. Memoria enviada a Pedro Gómez Labrador p. 3. 
de declararse campeón de las pretensiones y de los derechos ajenos, cuando necesita de todos sus esfuerzos para conquistar el trono que le han usurpado; cuando su propio triunfo, que tanto le interesa, no está aún decidido; y cuando su conciencia le impone el imperioso deber de no pensar en otra cosa sino en restablecer la paz en sus propios Estados para subsanar los males de sus amados súbditos»120.

Don Carlos manifestaba ser consciente de que la unión de las tres causas sería interpretada por Inglaterra y Francia como una provocación y que abocaría a todas ellas al fracaso; y hacía una declaración de principios por la que aseguraba que no buscaría más que el bien de sus súbditos, mantendría buenas relaciones con sus vecinos y respetaría su forma de gobierno.

El apartado referente al mantenimiento y restauración de las instituciones provinciales era el que mayores divergencias presentaba respecto a los dos textos anteriores (Memoria base y texto enviado a Turín). A pesar de que en el inicio se habla de instituciones provinciales, en todo el cuerpo del texto se alude exclusivamente a los Fueros de Navarra y Provincias Vascongadas, que en más de una ocasión se había comprometido a su mantenimiento, y se extendía en los razonamientos usados en el documento base sobre la inoportunidad de reiterar una promesa.

La parte novedosa del texto consistía en la minimización del valor de los fueros como elemento detonador de la sublevación:

«Estos naturales descansan ciegamente en la palabra de su Rey, y ni necesitan, ni desean, ni le piden nuevas protestas. Si hasta cierto punto es positivo que en el pronunciamiento de estas provincias haya tenido parte su celosa solicitud por sus instituciones locales, que con fundadísima razón consideran más al abrigo de su ruina bajo el paternal reinado de su legítimo soberano, que bajo el Gobierno revolucionario y que tiende todo a nivelar con sus absurdas teorías; nadie que conozca realmente el espíritu público de esta nación y en particular el de estas provincias dejará de estar muy convencido que en unas como en otras el principal móvil de su arrojado levantamiento, el estímulo más poderoso de la constancia de sus heroicos esfuerzos, han sido y serán siempre su firme adhesión a sus legítimos Reyes, el más puro entusiasmo por la Religión de sus padres y por las Leyes fundamentales de la Monarquía, y el más ardiente y justo amor hacia el digno sucesor de la Corona... «121.

Esta frase estaba destinada tanto a responder a ciertas informaciones que se propalaban en el extranjero sobre la importancia del factor foral, artículos sobre la administración de las Provincias Vascas, etc., y también al consumo interno.

Sorprendentemente, porque se trata de la única vez, se remite al documento enviado a Turín a fin de completar lo dicho sobre la cuestión de las instituciones provinciales.

120 A.R.A.H. 9/6740. Memoria enviada a Pedro Gómez Labrador p. 3-4.

${ }^{121}$ A.R.A.H. 9/6740. Memoria enviada a Pedro Gómez Labrador p. 5-6. 
La cuestión de la Inquisición es considerada «delicadísima y de cuya difícil naturaleza pocos están penetrados», es decir, se saca a relucir el razonamiento enunciado en los primeros párrafos, la escasez de personas realmente capacitadas para hablar de temas tan complejos. Con ello se estaba desautorizando a quienes hacían la propuesta.

El resto de la respuesta está en las coordenadas fijadas por el documento base de Carlos Cruz Mayor: el Rey es muy prudente, nunca ha dicho que va a restablecer la Inquisición, pero deja abiertas todas las posibilidades:

«Carlos V es cauto y reservado como lo exigen imperiosamente las circunstancias y su posición; pero nunca debe desconfiarse de un alma grande como la suya, ni suponérsele capaz de recurrir a medidas de represión o severidad por las que no clame el voto de sus súbditos, y que no exijan su verdadero bien y sus más caros y sagrados intereses; a medidas, finalmente, cuyas ventajas no superen los inconvenientes que puedan acompañarlas» ${ }^{122}$.

La respuesta dejaba abiertas todas las salidas y especialmente la de atender al grito de «ivivan las cadenas!».

El último punto que se responde es el relacionado con la amnistía que se mueve en líneas generales de acuerdo con las ideas del documento base. Se menciona la necesidad de distinguir entre descarriados y criminales; se recuerda que son reincidentes de 1820; se enumera una larga lista de agravios (asesinatos, quema de iglesia, muerte de prisioneros, etc.); y se menciona que los mismos Gobiernos que le solicitan la amnistía aplican duros castigos a los criminales y revolucionarios en su país. Y finaliza con un duro alegato contra quienes han realizado la propuesta:

«No; jamás, ningún hombre de juicio, a quien importe la paz del mundo y la felicidad de los pueblos aconsejará tan perjudicial sistema. Jamás se pretenderá que los que juzgan peligrosos para otros Estados se hayan de amparar y proteger en un país recién conmovido hasta sus cimientos por una horrorosa revolución»123.

El último párrafo del documento está dedicado a señalar la generosidad con que don Carlos trataba a los prisioneros, a los enemigos, etc.

\subsection{El documento entregado a la Embajada prusiana en París}

Pedro Gómez Labrador elaboró un documento más reducido para responder a Haber, y endurecido en algunas de las expresiones, que entregó sin firma

122 A.R.A.H. 9/6740. Memoria enviada a Pedro Gómez Labrador p. 7.

${ }_{123}$ A.R.A.H. 9/6740. Memoria enviada a Pedro Gómez Labrador p. 9-10. 
a Werther, tal como le había solicitado el diplomático prusiano ${ }^{124}$. En opinión de Labrador dicho texto acabaría en manos del monarca francés.

Labrador iniciaba el documento acusando al gobierno liberal de haber orquestado una campaña de calumnias, que son repetidas por los escritores «vendus à la révolution», y a continuación atacaba duramente a los prusianos por hacerse eco de tales críticas, «un gouvernement dont les sympathies pour la cause de S.M. ne sauraient être douteuses». Se mencionaba la forma irregular de realizar la comunicación, razón por la cual podía haberse decidido no contestar.

La primera cuestión, separar su causa de las de Francia y Portugal, era un breve resumen del documento de Labrador: don Carlos no confunde dichas cuestiones y no puede distraer sus fuerzas de la cuestión española; y menciona que la victoria se ha retrasado por la intervención de Francia e Inglaterra en favor de los liberales. Se abstiene de hacer menciones para el futuro sobre la actitud que adoptará una vez en el trono, como figura en el documento redactado por Cruz Mayor.

Sobre el mantenimiento de las instituciones provinciales, sigue el guión al pie de la letra, pero con detalles que es interesante reseñar. No habla de instituciones sino de franquicias, y obviamente sólo se refiere a las Provincias Vascongadas y Navarra. La respuesta es telegráfica:

«La Navarre et les provinces Basques ont ces franchises depuis leur réunion à la Couronne d'Espagne et tous ses souverains les ont religieusement maintenues. Elles n'ont point été abolies que pendant l'éphémère domination de l'usurpation révolutionnaire. Charles a prêté serment de les conserver et S.M. n'a jamais manqué à ses promesses» 125 .

El texto resulta lacónico y se eliminan todas las referencias a la nivelación, a la preocupación de don Carlos por el bien de sus súbditos, etc.

Sobre el restablecimiento de la Inquisición se limitaba a decir que no se había adoptado ninguna determinación al respecto ni se había hecho tan siquiera insinuaciones.

La respuesta a la propuesta de la amnistía era la más extensa, aunque no se salía de las líneas marcadas en el documento enviado por Cruz Mayor.

Se considera una cuestión muy delicada y sobre la que resultaba peligroso discutir en estos momentos. A continuación repite las ideas planteadas en el documento que se resume: no confundir criminales con descarriados, el buen corazón del Pretendiente, el ejemplo de otras naciones que castigan a los culpables, el listado de horrores, etc.

124 A.R.A.H. 9/6728. Despacho de Pedro Gómez Labrador, representante carlista en París $\left(4.04 .1836 \mathrm{n}^{\circ} 168\right)$ al Secretario de Estado carlista adjuntando el texto entregado a Werther. A.S.T. LL.MM. Francia 262. Despacho del Embajador sardo en París (3.05.1836 nº 1452) al Conde Solaro, con el mismo texto. El escrito tiene 4 páginas.

${ }_{125}$ A.R.A.H. 9/6728. Memoria entregada al Embajador prusiano en París p. 2-3 A.S.T. LL.MM. Francia 262. Memoria entregada al Embajador prusiano en París p. 2-3. 
Y finalizaba haciendo un llamamiento a las Cortes autoras de la propuestas para que tuviesen mayor confianza en las cualidades morales y de gobierno de don Carlos.

Quizá, como sugería Labrador, Luis Felipe había tenido algún tipo de participación en las propuestas enviadas a don Carlos, o al menos esa deducción cabe inferirse de sus palabras transmitidas por el Embajador sardo en París:

«... ce Prince [don Carlos] est mal entouré, qu'il ne connaît pas ses intérêts véritables qui seraient d'agir avec clémence et de donner aux Espagnols des garanties contre l'arbitraire et les réactions qu'ils redoutent sous son gouvernement» 126 .

Las respuestas comunicadas a las diferentes Cortes no habían satisfecho ninguno de los extremos solicitados, información que era de sobra conocida en todos los ámbitos. Incluso el Embajador español en París tenía conocimiento del desagrado de los protectores de don Carlos por la respuesta recibida ${ }^{127}$. Por esta razón, a pesar del impacto que supuso la sublevación de La Granja, don Carlos no se pudo beneficiar del reconocimiento de las Cortes que habían cerrado sus representaciones en Madrid.

Poco después de la ruptura total de relaciones, Labrador transmitía un nuevo mensaje, en esta ocasión proveniente del conde Pozzo di Borgo, Embajador ruso en París, quien había señalado que para el reconocimiento era necesario que don Carlos realizase una petición escrita a los soberanos de Austria, Prusia y Rusia, y que publicase una proclama prometiendo amnistía «por las faltas que no sean delitos». Para dar mayor fuerza a su argumento indicaba que Wellington había realizado la misma petición a don Miguel, petición que había sido desatendida por el monarca portugués, quien en estos momentos se encontraba fuera del trono en Roma. Un mes más tarde recordaba que aún no había recibido respuesta a la petición rusa ${ }^{128}$. Solaro.

126 A.S.T. LL.MM. Francia 262. Despacho del Embajador sardo en París (18.07.1836) al Conde

127 A.M.A.E. 1494. Despacho de Joaquín Francisco Campuzano, Embajador español en París $\left(13.11 .1836 \mathrm{n}^{\circ} 131\right)$ al M.A.E.

128 A.R.A.H. 9/6714. Despachos de Pedro Gómez Labrador (26.09.1836 nº 264; 23.10 .1836 $\left.\mathrm{n}^{\circ} 275\right)$ al Secretario de Estado carlista. El Embajador español en París [A.M.A.E. 1494. Despacho de Joaquín Francisco Campuzano, Embajador español en París (13.11.1836 n ${ }^{\circ}$ 131) al M.A.E.] transmite que «Don Carlos ha enviado un agente al Embajador de Rusia en esta Corte para tratar con él y deshacer la diferencia que existe entre el modo de pensar de D. Carlos y el Emperador en punto a la amnistía que éste pedía con categoría». En parecidos términos se manifiesta otro testimonio proveniente del bando carlista (B.N. Paris Mss. Espagne 585 fol. 444. «las potencias del Norte y con ellas Luis Felipe han propuesto al rey $1^{\circ}$ que si da una amnistía en esto no están todos conformes, es decir, el Austria y Prusia que la dé de la manera que crea más conveniente, y la Rusia por clases como ella lo hizo en Polonia; y $2^{\circ}$ que no debe establecer la Inquisición. Si conviene el Rey en estos dos puntos están prontos a dar cuanto dinero necesite el Rey. Veremos lo que hacer. Que no habrá Inquisición es seguro, lo sé positivamente». 
Desde la Corte carlista se respondió que el asunto estaba ya contestado en anteriores despachos, es decir, se mantenía en una posición inamovible ${ }^{129}$. No resultaba extraño que Labrador transmitiese a sus superiores una visión muy pesimista sobre las relaciones que mantenía con los Embajadores de las Cortes conservadoras:

«En punto a acudir continuamente a la protección de las Potencias del Norte, lo hago con suma repugnancia, pues me reconvienen sus agentes con que no tenemos ninguna condescendencia con sus soberanos ni hacemos caso de sus consejos; y añaden que difícilmente reconocerán a S.M. mientras no haya publicado una declaración de que no se restablecerá la Inquisición ni hará castigar como delitos los yerros de entendimiento y los efectos de la flaqueza humana»130.

Pero la presión seguía de forma directa e indirecta, Carlos Alberto incluso hacía estos comentarios ante enemigos de los carlistas como el embajador británico a quien señalaba que don Carlos carecía de hombres con capacidad ${ }^{131}$. Metternich planteó a Alcudia la necesidad de una mejora en los contenidos de la prensa carlista, especialmente en lo que calificaba de la parte política para el extranjero; y para ayudar en ello propuso «mandar inmediatamente a ese Cuartel Real un sabio en esta clase de literatura» ${ }^{132}$. Tras esta propuesta se encontraba evidentemente un nuevo episodio de presión, a juzgar por la minuta de respuesta: que «no siendo posible ni político por ahora decir ni promover otra cosa que lo que ya se ha hecho en las proclamas dadas por S.M.» se desestimaba el ofrecimiento.

Unos meses más tarde, don Carlos con motivo de la Expedición Real remitió un escrito al Marqués de Labrador «acerca del sistema de gobierno que el Rey Nuestro Señor tiene intención de seguir cuando se halle en posesión del trono de sus mayores» ${ }^{133}$. Pero en opinión de Labrador los términos con que se expresaba («promesas de reinar como padre, de establecer un gobierno justo y suave») no resultaban suficientes para las Cortes conservadoras, tal como le habían expresado los Embajadores de las Cortes conservadoras en París en diversas ocasiones. En apoyo de sus tesis señalaban que en los dos períodos de reinado de Fernando VII se había prometido las mismas cosas y la realidad había sido completamente diferente.

\section{Labrador}

129 A.R.A.H. 9/6714. Despacho del Secretario de Estado carlista (2.11.1836) a Pedro Gómez

${ }_{130}$ A.R.A.H. 9/6714. Despacho de Pedro Gómez Labrador (30.09.1836 n 265) al Secretario de Estado carlista.

${ }_{131}$ Roselli, Nello. Op. cit. p. 658.

132 A.R.A.H. 9/6747. Despacho del Conde de Alcudia (12.12.1836 $\mathrm{n}^{\circ}$ 618) al Secretario de Estado carlista.

${ }_{133}$ A.R.A.H. 9/6713. Despacho de Pedro Gómez Labrador (11.08.1837 nº 11) al Secretario de Estado carlista. 